\title{
Formación y articulación de un concejo fronterizo: Jaén en el Siglo XIII
}

\author{
Eva Ma Alcázar Hernández \\ Universidad de Jaén
}

\section{INTRODUCCIÓN}

En el presente artículo exponemos nuestro análisis de la fase inicial de instauración en el Alto Guadalquivir de uno de los concejos de realengo peor conocidos de todo el ámbito castellano bajomedieval, el que construyeron los cristianos en torno a Jaén, una vez que la ciudad cae en su poder, a principios del año 1246.

La metodología de nuestro trabajo intenta armonizar las informaciones aportadas tanto por las fuentes escritas, muy escasas, como por las fuentes arqueológicas, especialmente trabajos de prospección, conscientes de que cada sociedad tiene un tipo de organización del espacio y, por lo tanto, éste sufrirá variaciones tanto en las diversas etapas evolutivas de aquélla, como con las transformaciones sociales y materiales que supone el cambio de una sociedad por otra. Por lo tanto, el análisis de las huellas dejadas en el espacio por una sociedad, debe ayudarnos a la reconstrucción de los perfiles de aquella (GARCÍA DE CORTÁZAR, 1988). Así, a los documentos escritos, se deben añadir las aportaciones de la Arqueología, la Geografía, la Toponimia y la Antropología.

El Concejo, entendido como una unidad de organización social feudal del espacio correspondería, según nuestra metodología, a una unidad espacial analítica denominada Territorio Político, circunscrito al "espacio producto de las prácticas de poder que un grupo social desarrolla a partir de la aceptación del hecho por la totalidad del mismo"; en el Territorio Político se conjugarían dos espacios distintos, uno, político-económico, definido "por las estrategias que la estructura de poder impone para su reproducción", y otro, ideológico, o espacio de legitimación, el cual "sustenta la legitimidad del uso de la fuerza en el espacio caracterizado por el bloque que tiene una posición preeminente en la estructura de poder. No obstante, este último espacio, en cuanto es producto de la pretensión de identidad de la totalidad del grupo, no es sólo el espacio donde ejerce violencia sobre otro, «legítimamente», (...), sino el espacio de identidad política consensuado por todos los grupos sociales" (RUIZ RODRÍGUEZ, MOLINOS MOLINOS, RÍSQUEZ CUENCA, 1998: p. 26).

El trabajo que presentamos aquí refleja una parte de la investigación que llevamos a cabo actualmente sobre este Territorio Político surgido en torno a la ciudad de Jaén en los siglos bajomedievales, centrándonos en la exposición e interpretación de las vicisitudes históricas que acompañaron su instauración y consolidación, estudiando la primera definición de sus fronteras jurisdiccionales, sus originales formas de poblamiento y la jerarquización espacial de los asentamientos, la distribución espacial y el aprovechamiento de los espacios productivos y de los recursos naturales, y, por último, la atribución y reparto social de los mismos.

La Ciudad de Jaén en la Baja Edad Media ejerció su dominio político y económico sobre un territorio cuya extensión, a pesar de las fluc- 
tuaciones sufridas desde su definitiva conquista por los ejércitos castellanos en 1246, y especialmente en los siglos XIV y XV, nunca descendió de los $1.000 \mathrm{~km}^{2}$, llegando a su máxima expansión tras finalizar la Guerra contra Granada, en 1492, momento en el cual el Concejo contaba con más de $1.600 \mathrm{~km}^{2}$.

El Concejo ocupaba, aproximadamente, una octava parte de la actual provincia de Jaén, que como vemos en la FIGURA I, está, hoy en día, compartimentada en 16 términos municipales diferentes, disgregación causada por el proceso de independencia de las aldeas bajo su tutela, que comenzó a mediados del siglo XVI. La única excepción es la de La Guardia de Jaén, que aparece como señorío al menos desde finales del siglo XIII, al sur del dominio territorial de la Ciudad.

La Tierra de Jaén conformaba una banda territorial delimitada en sus grandes líneas por hitos geográficos bien identificables (FIGURA 2): al norte, el río Guadalquivir, al este, el Arroyovil, al oeste, el Arroyo Salado de los Villares, y al sur las llamadas Sierras Sur de Jaén y Sierra Mágina.

Este territorio no presenta características homogéneas en cuanto a su topografía, a su base geológica o a sus suelos, ya que abarca parte de dos dominios geomorfológicos completamente diferentes:

Al norte, la Depresión del Guadalquivir, en concreto, su sector más oriental, denominada Campiña de Jaén, que se considera generalmente dividida en dos zonas, la Oriental y la Occidental, por el cauce del río Guadalbullón, que, naciendo en el corazón del prebético jiennense, discurre de sur a norte hasta tributar sus aguas en el Guadalquivir, siendo la arteria principal de una red de drenaje que se abastece principalmente de los ríos serranos, aunque también de algunos importantes arroyos de la Campiña.

La Campiña Oriental es considerablemente más estrecha que la Occidental, de sur a norte la surcan pocos pero importantes arroyos, como el Arroyovil y el Salado de Torrequebradilla. La característica más señera de estas tierras es su salinidad, $y$, en general, su mala calidad para el cultivo.

Por lo que respecta a la Campiña Occidental, su red hidrográfica es más compleja y abundante que en la Campiña Oriental, recorriéndola numerosos arroyos. Por otra parte, las tierras de la Campiña Occidental son más ricas, y tradicionalmente han estado más pobladas, siendo protagonistas de una explotación agrícola más intensa.

Al sur, está el segundo dominio geomorfológico, las sierras pertenecientes al Frente Externo de las Cordilleras Béticas, que durante la ocupación musulmana estaba repartida entre las Coras de Ŷayyān y de llbïra. En estas sierras se ubicó la zona de fricción fronteriza entre el Concejo de Jaén y el Reino Nazarí de Granada, durante toda la Baja Edad Media.

Este ámbito territorial será uno de los escenarios en los que se llevará a cabo, desde principios del siglo XIII, la supresión violenta de una formación social, la islámica en su fase almohade, y la instauración de un régimen político y socioeconómico radicalmente diferente: $\mathrm{El}$ hispano-feudal, impuesto por el Reino de Castilla después de la Conquista.

No se trató, pues, de un largo y lento proceso de transición social, sino de una implantación traumática, que dislocó la anterior organización no ya sólo administrativa o política, sino, y sobre todo, la del poblamiento, los usos del suelo o la estructura de la propiedad, así como la percepción del territorio que poseía la comunidad vencida.

El territorio objeto de este estudio fue un distrito de realengo, aunque a lo largo del tiempo partes del mismo fueron segregadas y convertidas en señoríos, o territorios de señorío se incluyeron temporalmente en las tierras del Concejo, siguiendo los vaivenes de la situación política general.

Los castellanos, una vez que la ciudad de Jaén cae definitivamente en sus manos, en 1246 , la utilizarán como el núcleo articulador de todo este territorio, imponiendo un modelo de orde- 
nación territorial plenamente "probado" y consolidado en otras muchas ciudades castellanas: la comunidad de Villa y Tierra o Concejo, considerada como la unidad de organización social del espacio más compleja de la Castilla hispano-feudal.

En la práctica, se trata de un distrito compuesto por una población de cierta entidad, con rango de ciudad o villa, que tenía jurisdicción sobre un territorio con un número variable de aldeas, así como sobre las tierras, las aguas, etc. con amplias facultades para organizar el territorio, lo que las diferencia de las islámicas.

En función de este esquema organizativo, Jaén, se convertirá en la cabeza de un sistema jerárquico de articulación del poblamiento, basado en las relaciones "piramidales" establecidas entre la ciudad y sus aldeas, y la ciudad y sus cortijos, que permitirá a Jaén controlar su alfoz.

El proceso de la conquista militar de las tierras de Jaén es bien conocido, gracias a las Crónicas de la época. Por lo que respecta a la ciudad de Jaén, la ofensiva cristiana se concretará entre 1244, en que Fernando III inicia el ataque y conquista de las fortalezas que rodean la ciudad (Arjona, La Guardia, Pegalajar), y febrero de 1246, mes en el que, tras largo asedio, Jaén es entregada por Muhammad I a los ejércitos castellanos trámite capitulación. Al mismo tiempo, el nazarí se reconocía como vasallo del rey castellano, al que pagaría un tributo anual de 150.000 maravedíes, asegurándose el señorío sobre el resto de su territorio. Con esta acción finaliza la conquista militar del territorio giennense, y queda también constituido el Reino de Granada, reconocido y vasallo del rey de Castilla, y cuyas fronteras en este sector quedan ya delimitadas en las sierras al S y SE de la ciudad de Jaén. La frontera activa con el Reino nasrí condicionará de forma total la organización del territorio dominado por el Concejo de Jaén.

\section{REPOBLACION Y REPARTIMIENTO}

De su proceso de organización territorial, sabemos poco o nada, sólo que Fernando III residió en la ciudad durante unos seis meses después de su conquista, organizando el repartimiento -del cual no nos ha llegado el contenido-, la instalación de pobladores y la articulación de la institución de gobierno concejil. El Fuero concedido fue, como en gran parte de los concejos de realengo andaluces, el de Toledo.

La conquista castellana provocó en las regiones andalusíes anexionadas enormes cambios, al implantar los conquistadores los esquemas organizativos de la sociedad feudal, que sustituyeron brusca y rápidamente a la anterior organización islámica, radicalmente diferente: "los procesos de «repoblación» son buen testimonio de estos cambios puesto que no sólo obedecen a un programa de poblar comarcas vacías de población sino que, sobre todo, sirven como instrumento mediante el cual integrar los territorios recientemente conquistados a los mecanismos sociales y económicos de la sociedad feudal" (IIMÉNEZ SÁNCHEZ, QUESADA QUESADA, 1992: p. 52).

Indisolublemente unidos a las repoblaciones, están los "repartimientos", los mecanismos de distribución de tierras, primero entre quienes habían participado en la conquista y más tarde entre quienes acudían a poblarlas (GONZÁLEZ JIMÉNEZ, 1987), y que servían a los conquistadores para adecuar a los parámetros castellanos los territorios urbanos andalusíes.

En lo que atañe al repartimiento de Jaén y sus aldeas, no se ha conservado ninguno de los Libros de Repartimiento, lo que impide conocer mínimamente cual fue la situación que se planteó tras la conquista. Hay algunos datos sueltos, contenidos en diplomas o transmitidos por cronistas posteriores que pudieron ver algunos de ellos, aunque apenas son suficientes para hacernos una idea de cual fue la situación de partida.

La I Crónica General (cap. 107I) resalta los propósitos repobladores emprendidos por el rey inmediatamente después de la conquista. Según esta fuente, el rey:

"des y enbió por pobladores a todas partes, enbiando prometer grandes libertades a quantos 
y veniesen a poblar; et venieron y muchas gentes de toda la tierra, et mandolos partir la villa et los heredamientos a todos muy comunalmente, a cada uno segunt pertenescie, et desy aforolos et conpliolos quanto les prometiera" '.

J. González recopiló los escasos documentos que se conservan sobre el reparto de la ciudad, según los cuales Fernando III entregó a las diferentes órdenes militares que habían participado en la conquista, la de Santiago, la de Calatrava y la de San Juan, diversas casas expropiadas a destacados miembros de la comunidad vencida ${ }^{2}$.

Pero además de esas concesiones especiales, el reparto del conjunto de la ciudad entre quienes habían participado en la toma, o acudieron a poblarla, fue encargado por el rey, quien a finales de agosto partió para Sevilla, a Don Ordoño Álvarez, señor de Noroña y primer alcaide de Jaén, que debió efectuarlo entre agosto y diciembre de 1246, siguiendo las instrucciones del monarca (GONZÁLEZ GONZÁLEZ, (1980-1986): vol. I, p. 436).

A ello podemos agregar que aunque no se conservan documentos, parece probable que la Iglesia recibiera todas las mezquitas que había en la ciudad, que se convertirían en igle- sias $^{3}$. Cabe suponer también que los edificios fueron acompañados de buena parte de los bienes habices de las mismas. Así mismo, el rey se reservaría también una parte de los edificios ${ }^{4}$.

Lógicamente, los términos de la ciudad fueron igualmente repartidos, aunque, de nuevo, las noticias son muy escasas, y sólo lentamente, a partir de menciones casuales es posible reconstruir algo de lo distribuido.

Sabemos que, como ocurrió en otros muchos repartimientos andaluces, como el de Sevilla, algunos de los familiares del rey fueron favorecidos con una serie de donadíos en el alfoz jiennense. Así, su hermano, el Infante Don Alfonso de Molina obtuvo una heredad, en concreto una aldea, cuyo nombre no aparece especificado en la documentación, y de la que sólo se sabe que en 125 I ordenó a sus hombres pagar diezmos ${ }^{5}$.

Otros personajes importantes obtuvieron donadíos en Jaén que incluían alguna población, como es el caso de Villardompardo, que según afirma Espinalt en su Atlante Español era una pequeña alquería abandonada por sus habitantes que, tras la conquista castellana, fue poblada por D. Pedro Aznar o D. Pedro Pardo,

I Primera Crónica General de España. Alfonso X, rey de Castilla. Editada por Ramón Menéndez Pidal; con estudio actualizador de Diego Catalán, Vol. VII, 1977. Universidad Complutense. Madrid.

2 Fernando III entregó a la Orden de Santiago, el 28 de febrero de 1246, las casas en Jaén que "habían sido de Rabi Zulema"; a los calatravos, les concedió, el 31 de marzo, las casas "que habían sido del Arraez Audalla, con sus establías, horno y demás pertenencias"; la Orden de San Juan también fue favorecida por el rey el 10 de mayo, quedándose con las casas que "habían sido de Aben Nazar, cerca de Santa María Magdalena". Otros personajes que habían participado en la conquista de Jaén también fueron heredados, como el Comendador de Martos, quien obtuvo el 26 de septiembre "las casas que había tenido en Jaén el Alcayat Aben Margoan". Posteriormente, el I de marzo de 125I, dio a la Iglesia y obispo de Córdoba, "un par de casas en Jaén con su bodega y establía" (GONZÁLEZ GONZÁLEZ, (1980-1986), vol. I, p. 435-436).

3 La transformación está atestiguada en el caso de las iglesias de la Magdalena y de San Juan, así como en el de la propia mezquita aljama que se convertiría en iglesia de Santa María, ubicada en parte donde se sitúa la catedral actual (AGUIRRE SADABA, I982, pp. 196-197; PÉREZ MARTÍNEZ; ALCÁZAR HERNÁNDEZ, 1993, pp. I4I-I46; SALVATIERRA CUENCA, I993, pp. I58-I59).

4 Estos comprenderían al menos el palacio real, que debía ocupar la manzana en la que hoy están el Archivo Histórico Provincial y el palacio de Los Uribe, ya que sabemos que el conjunto fue cedido por Juan I a los Dominicos. Igualmente, se cree que Fernando III se reservaría una amplia propiedad en las afueras de la ciudad, La Huerta del Rey en lo que luego será el barrio de San Ildefonso, y que Pedro I entregaría a los franciscanos para la construcción de su convento, estando hoy allí la Diputación provincial (SALVATIERRA CUENCA, 1993, pp. 159-160).

5 "Co(n)nSçuda coSa Sea a todos q(uan)tos eSta carta uieren cuemo yo Jnfa(n)te do(n) alfonSo Se(n)nor de Molina (e)t de MeSa ma(n)do a todos aq(u)ellos om(m)es q(ue) la mi he(re)dat de Jahen e de Ybros por mj touie(ren) q(ue) den todo el diezmo q(ue) yo ouiere al Ob(is)po de Jahen..." (SEGURA MORENO, 1976, p. 190). 
al concedérsela Fernando III en $1245^{6}$. Sin embargo la primera noticia documental segura es de 125|, cuando el Villar de Don Pardo se menciona en la delimitación de términos entre Jaén y Martos, establecidos por el propio rey, que ubica precisamente en esta localidad uno de los hitos de la división 7 , quedando dentro del realengo jiennense.

A parte de estos territorios, también entregó posesiones dentro de los términos del Concejo a las diversas órdenes militares, pero se guardó mucho de que estas fueran muy extensas (FIGURA 3).

Así a la Orden de Santiago le entregó "la torre de Maquiz, con quince yugadas de heredad junto a ella; la que había sido de Mezquiriel, con dos pasadas de molinos, quince aranzadas de viña y cuatro de huertas" (GONZÁLEZ GONZÁLEZ, opus cit:: vol. I, nota 116 y vol. III, documento $n^{\circ}$ 735). La primera estaba situada en Cerro Maquiz, junto a la desembocadura del río Guadalbullón en el Guadalquivir, y en el que se ha localizado la antigua ciudad romana de lliturgi. En 1646, cuando Rus Puerta escribe su Corografia sobre el Reino y Obispado de Jaén, Maquiz aún pertenecía a la Orden de Santiago, siendo un anexo de su encomienda de Albanchez. Teniendo en cuenta el terreno concedido, unas 268 hectáreas $^{8}$, cabe suponer que les cedería todo este imponente cerro amesetado. En cuanto a la segunda donación, no hemos conseguido rastrear el topónimo Mezquiriel, por lo que es una incógnita su ubicación, aunque, a juzgar por los tipos de cultivo (viñas y huertas), lo reducido de su superficie (8,50 has en total) y la mención a los molinos, debía de situarse cerca de un río o arroyo de caudal importante.
Un donadío mucho menor (17,5 has en total) recibió la Orden Militar de Calatrava: "veinte aranzadas de heredad en Espeluy, un arco en el Guadalquivir, quince aranzadas de viña en Jaén, en el Pago Almorg, allende la torre de Fuentes; cuatro de huerta, una pasada de Molino, que había sido del «vieio, so» la huerta de Lexix" (Ibídem). Espeluy se encuentra a $34 \mathrm{~km}$ al norte de Jaén, a orillas del río Guadalquivir, y en él se ubicaba uno de los pocos vados que permitían pasar el río en esta zona, por lo que constituía un importante nudo de comunicaciones. Había sido conquistado durante la campaña militar contra Quesada, en 1224 , y en él edificaron los castellanos una fortificación, al parecer levantada sobre las ruinas de la islámica, derruida por Fernando III tras su conquista (CAZABÁN LAGUNA, 1924: p. 336).

En cuanto a la torre de Fuentes, aunque, en principio no está identificada, es factible la posibilidad de que se tratase de la futura aldea de Fuente del Rey (actual pueblo de Fuerte del Rey), en la que, efectivamente, existía una torre en la época de la conquista castellana. Según esta hipótesis, la concesión estaría ubicada al norte de esta localidad. Dicha suposición puede avalarse por el hecho de que, a cuatro kilómetros al nordeste de Fuerte del Rey, se ubica el Cortijo de Macarena, muy próximo al Arroyo del Platero o de las Piedras de Yeso, afluente del Guadalbullón, y junto al que nace un manantial de gran importancia, dada la escasez de agua potable de la zona.

El profesor Tomás Quesada propuso identificar este cortijo (QUESADA QUESADA, 1994: p. 30). con el del mismo nombre visitado por los regidores del Cabildo giennense en $|40|$, en

6 Este señor era, según Espinalt "Caballero de lo más ilustre de Aragón, y Valencia" (ESPINALT GARCÍA, I775, p. 335), en lo que coincide con Argote, que en su Nobleza de Andalucía, lo hace hijo de un guerrero destacado en la Batalla de las Navas de Tolosa: "Don Aznar Pardo, ricohombre de Aragon, mayordomo mayor del rey D. Pedro, y señor de la villa y castillo de la Casta", añadiendo que este Pedro Pardo también fue heredado en la torre de Gil Olid, "y su hacienda y nombre se consumió por casamientos en el linaje de Dávalos" (ARGOTE DE MOLINA, I588, p. 103).

7 Bulario de la Orden Militar de Calatrava, 1762. Reedición El Albir, 1981, Scriptura XVIII, p. 95.

8 Para la conversión de estas medidas de superficie medievales a las del sistema métrico actual, hemos utilizado las indicaciones que da el profesor M. González Jiménez (1988, p. 109), que para el Reino de Jaén utiliza la equivalencia I yugada - 40 aranzadas; mientras que la equivalencia entre aranzadas y metros cuadrados es I aranzada - $4400 \mathrm{m2}$ (1977, p. 170). 
su expedición de control de dehesas boyales. La importancia de estos datos reside en que, en 1401, la propietaria del Cortijo de Macarena era la Orden Militar de Calatrava.

Por lo que se refiere al tercer lugar en el que se les concede tierras a los calatravos, dentro del término de Jaén, la "huerta de Lexix", creemos poder identificar el lugar con el Pago de Lerix o Vado Lerix, situado al sur de Jaén, a mitad de camino entre esta ciudad y el castillo serrano de Otíñar, y que, como describe Madoz (p. 99), es el lugar en el que al río Quiebrajano, "a una legua de su nacimiento[...], se le agrega por el lado izquierdo el río que viene de los Villares", cambiando entonces su nombre por el de Río Jaén. Actualmente, a este lugar se le conoce como Vado Lerín o Val Lerín, dentro del Pago del Puente de la Sierra, que tradicionalmente ha estado ocupado por huertas, aunque ahora se ha convertido casi totalmente en una urbanización de chalés.

Los calatravos no se conformaron con tan mezquino patrimonio, y en las décadas sucesivas se hicieron con más tierras dentro del término jiennense, por lo que se ve a través de la compra, lo que es, cuanto menos, curioso, ya que el Fuero de Toledo prohibía explícitamente enajenar heredades a favor de las Órdenes. En la $2^{a}$ Recopilación y Confirmación del Fuero de Toledo realizada por Fernando III en 1222, que constituye la última y definitiva redacción del Derecho vigente en la Ciudad, puede leerse:

"Quod nullus de Toleto, sive vir sive mulier, possit dare vel vendere hereditatem suam alicui Ordini, excepto si voluerit eam dare aut vendere Sanctae Mariae de Toleto, quia est sedes civitatis; sed de suo mobili det quantum voluerit secundum suum forum. Et Ordo qui eam acceperit datam vel emptam, amitat eam. Et qui eam venderit amitat morabetinos, et habe- ant eos consanguinei sui propinquiores" (GARCÍA GALLO, 1975: p. 488).

Además, ésta fue la redacción que el rey concedió a las ciudades andaluzas de Córdoba ( I24I), Sevilla (1250) y Carmona (1252), por lo que podemos encontrar la misma prohibición en sus fueros ${ }^{9}$.

Entre 1256, fecha del primer acuerdo establecido entre la Orden y el Obispado de Jaén sobre los diezmos que aquélla debía pagar en sus tierras, y la ampliación del mismo, firmada en enero de 1283, los freires adquirieron nuevos heredamientos: "...(e)t p(ro)metemos otros si de dar deçima del h(e)redamie(n)to q(ue) c(om)pramos en eSpeluy de don(n)a marin(n)a [...] (e)t en la caSa del Judio q(ue) es cerca dos barrios..." (SEGURA MORENO, 1976: p. 217). La localización dentro del término jiennense de la Casa del Judío es sólo una conjetura -ya que no hemos podido rastrear el topónimo en la documentación conservada-, sin embargo, sí que está constatada en época bajomedieval la existencia, a doce kilómetros al noroeste de la ciudad de Jaén, del Cortijo de Dosbarryos (QUESADA QUESADA, opus cit: p. 30), el cual se ubicaba a un escaso kilómetro y medio del Arroyo del Judío, topónimo este último también constatado abundantemente en época bajomedieval.

Por último, también se ha conservado referencia a la donación de "siete yugadas de heredad, siete aranzadas de viña y dos de huerta" (GONZÁLEZ GONZÁLEZ, opus cit:: vol. I, p. 435) a la Orden de San Juan, sin que se especifique el lugar (o lugares) donde se ubicaba la donación. En la delimitación realizada en 125 I por Fernando III entre la encomienda calatrava de Martos y el Concejo de Jaén, se hace mención a una "torre del Ospital", que podría considerarse como posesión de la Orden de San Juan, dado que también era conocida como Orden del Hospital o de los hospitalarios. Recientemente

\footnotetext{
9 Así por ejemplo, el Fuero de Córdoba dice exactamente lo mismo al respecto: “...Que ningunt ome de Córdoba varon, é muger, non pueda vender, ni dar su heredat á alguna órden, fueras á Santa María de Córdoba, que es catedral de la cibdat; mas de su mueble de quanto quisiere segunt el fuero de la villa, é la órden que la rescibiere comprada, ó donada, piérdala, é el vendedor pierda los dineros, é áyanla los sus parientes los mas cercanos". (BURRIEL, I800, p. 46I).
} 
(CASTILLO ARMENTEROS, LARA JIMÉNEZ y CASTILLO ARMENTEROS, 1989: p. 373) ha sido propuesta la identificación de esta torre con los restos de una fortificación situada a unos nueve kilómetros al oeste de Torredonjimeno, que actualmente recibe el nombre de Torre de Fuencubierta ${ }^{10}$. En cuanto a la superficie concedida, 125 has de heredad, 3 de viña y menos de I hectárea de huerta, es muy superior a la concedida a los calatravos, aunque sólo supone un poco más de la mitad de la de los santiaguistas.

Junto a Jaén estarían, así mismo, las "seis aranzadas de viña y tres de huerta en la Puerta de Granada, y seis yugadas de heredad en Fuente Peniella" concedidas a la Iglesia y Obispo de Córdoba (GONZÁLEZ GONZÁLEZ, opus cit: vol. III, documento $n^{\circ}$ 776). La referencia a la Puerta de Granada, al sur de la ciudad, confirma la existencia de huertas en esa zona, regadas por el manantial de Santa María, mientras que la heredad debía de estar en el pago de la Fuente de la Peña, a un kilómetro al sur de Jaén, donde se localiza un importante manantial de agua, y en el que se ubicarán las huertas y campos llamados de Valparaíso, regados por el Arroyo Reguchillo. Esta abundancia de agua hace que las 107 hectáreas de heredad concedidas puedan considerarse de gran valor.

En total, la superficie que Fernando III donó a las Órdenes Militares fue de, aproximadamente unas 535 hectáreas, nada impresionante, si tenemos en cuenta la cantidad de tierra a repartir, pudiéndose hablar de "gran propiedad" tal vez sólo en el caso del donadío recibido por los santiaguistas formado por Maquiz y la torre de Mezquiriel, que superaba las 275 hectáreas. Aunque desde luego, eran propiedades ubicadas en tierras ricas y con abundante agua, además de contar, en el momento de la donación, con cultivos altamente apreciados como las huertas y las viñas.

Así pues, la distribución mayor debió de hacerse entre los nuevos pobladores. Por desgracia, prácticamente nada se sabe del reparto de heredamientos, es decir, "de aquellos bienes que correspondieron a los pobladores propiamente dichos" "I. J. González sólo pudo recoger la noticia, casi anecdótica, de que "entre otros caballeros que acudieron al reparto de Jaén estaba Fernando Osórez, cuya viuda habría de empeñar más tarde su heredamiento" (Ibídem, p. 436).

Además, también hay que tener en cuenta que, al igual que en la ciudad, el rey se reservaría una parte del alfoz ${ }^{12}$, que quedaría pues sin repartir, y que con el paso del tiempo pasaría a manos concejiles, en forma de tierras de propios, o bien sería objeto de nuevas donaciones.

\section{LOS PRIMEROS SEÑORÍOS}

De hecho el mismo Fernando III creó dos señoríos a costa de las tierras realengas de Jaén. En general, los señoríos creados por Fernando III en el Alto Guadalquivir fueron concedidos con el fin de que sus beneficiarios se encargasen de controlar las zonas fronterizas más conflictivas, con un sistema autónomo y flexible que garantizara una defensa efectiva.

Estas son las razones que lo llevaron a crear, muy próximos a Jaén dos señoríos, cuya existencia debió de resultar incómoda para el Concejo, ya que frenaban sus posibilidades de expansión por el sur (FIGURA 4): el del Obispado de Jaén sobre el castillo de Cárchel, y el de La Guar-

\footnotetext{
10 Hoja Cartográfica I: 10.000: 94622; Coordenadas UTM: 406950, 4I 82030.

I I Definición dada por el profesor M. González Jiménez, que continúa diciendo que "entre ellos pueden distinguirse diversas categorías que corresponden básicamente a funciones militares. En términos generales tres son los grupos principales de pobladores recogidos en los textos de la época: los «caballeros de linaje» o «caballeros hidalgos», los «caballeros ciudadanos» o «caballeros villanos» y los «peones» o simples pobladores" (GONZÁLEZ JIMÉNEZ, 1988, p. I 08 y s.).

12 No hay noticia directa sobre Jaén a este respecto, pero sí de otras ciudades del Alto Guadalquivir, como Baeza, en la cual el rey se reservó un cuarto del total para su libre disposición, como se desprende del Privilegio firmado por Fernando III en I236 por el cual le dona al Obispo de Baeza "...Seys lugos de bueyes a an(n)o (e)t uez en Vbeda (e)t una Rueda de Molino en lo del Conçeio (e)t Seys ara(n)çadas de vin(n)as en el mjo q(uar)to" (SEGURA MORENO, 1976, p. I83).
} 
dia en manos de $D^{\mathrm{a}}$ Juana de Ponthieu, esposa de Fernando III, encargados ambos de proteger las vías directas de acceso a Jaén por el estrecho valle del Guadalbullón, y que habían sido conquistados en la misma campaña de I 244 en que también se tomaron Arjona, Pegalajar, Bexix y Cazalla.

Con respecto al primero, parece que la concesión fue realizada al obispo Pascual y a sus sucesores por Alfonso X en 1253, con la exigencia expresa de que "fagades deste castiello a mi e a los que regnaren despues de mi en Castiella e en León, guerra e paz e vasallage como e a rey e a sennor, por razon deste castiello" (RODRÍGUEZ MOLINA, 1986: p. 149). No obstante, podría ser que el texto sea una confirmación de una cesión precedente realizada por Fernando III, ya que un año antes, el obispo Pascual ya disponía del castillo como suyo; así se desprende del compromiso transitorio firmado con la Orden Militar de Calatrava el 6 de mayo de 1252, hasta que llegara el visto bueno del Apostólico al acuerdo -cuya redacción definitiva fue de 6 de Mayo de 1256- al que habían llegado ambas instituciones sobre el reparto de los diezmos y rentas eclesiásticas que gravaban las tierras y propiedades que los calatravos tuvieran dentro del Obispado jiennense ${ }^{13}$.

Por lo que se refiere a La Guardia, la cuestión de que fuera un señorío desde el primer momento la planteamos por ahora sólo como hipótesis, partiendo de la referencia que hace
Julio González del hecho de que Fernando III concedió a su mujer en Jaén "un donadío con la torre de Montíar" (opus cit., vol. I, pp. 104 y 106).

El interrogante que nos planteamos es si esta torre es la misma Montíjar que asoló Fernando III a su vuelta de la campaña de 1226 (Montejícar, Marchena, Bonil, Pegalajar y Montíjar), que por el itinerario seguido y por su similitud con el topónimo Mantisa, ha sido considerada desde antiguo como la población de La Guardia ${ }^{14}$. J. González también parece considerarlo así, ya que, aunque no lo comenta ni propone ninguna identificación, une las referencias a ambos lugares en el índice final de su obra. No obstante carecemos de otros documentos que indiquen las vicisitudes de esta localidad, que en 1295 ó 1296 aparece en manos de Juan Ruiz de Baeza (ARGOTE DE MOLINA, 1588: p. 345), sin que conozcamos el proceso de cambio.

\section{EL FUERO}

Inicialmente, el éxito repoblador debió de ser importante, acudiendo muchos nuevos habitantes, ante las condiciones ofrecidas, que suponían mejoras en su situación, ya que las cargas a satisfacer eran menores que las que debían soportar en sus tierras de origen, donde la presión nobiliaria se había ido incrementando constantemente. De esta forma, parece que se creó una amplia capa de propietarios campesinos

\footnotetext{
13 "Conoscida cosa sea à quantos esta Carta vieren, è oyeren, como nos Don Pascual, por la gracia de Dios Obispo de Jaen, è el Cabildo des mismo lugar, prometemos firmemente por Nos, è por todos nuestros successores, que sì alguno de la eglesia de Jaen por sì, ò por la eglesia viniere contra la composicion, que havemos con el onrado varon Don Per Ibañez Maestre de la Orden de la Cavalleria de Calatrava, è con el Convento dese mismo lugar [...], que Nos seamos tenudos [...] de defender la composicion por Nos, è por nuestras despensas, fasta que sea confirmada del Apostoligo [...], è si lo non ficiessemos, que pechemos à la Orden de plano diez mill maravedis alfonsis, et damos por fiador, è por principal debdor à Maestre Martin Arcediagno de Jaen [...], è apoderamoslo [...] en el castiello de Carchel, è en todas las rendas, que ì havemos, è en el cortijo de Bexixar, è en el olivar, è en la huerta, è en el heredamiento todo, que í havemos, è en todas las viñas, que nos dio el Rey Don Fernando en Baeza, è apoderamoslo. Otrosi en Mesura, è en Canalegias aldeas, que son en termino de Baeza, è en los vassallos, è en las viñas, è en todo el heredamiento, que ì havemos [...] Fecha la Carta en Martos, Sabado seis dias no mas andados de Mayo, so el Era de mil docientos è noventa" (Bulario de la Orden Militar de Calatrava, I762. Reedición El Albir, 198I, Scriptura XIII, pp. 88 y s.).

14 Esta identificación la daba como segura Ximena Jurado en 1654, quien, refiriéndose a la campaña en la que Fernando III conquista Arjona, dice: "La Historia General de España fol. 4 I 4 pone también en esta ocasion la conquista de Pegalajar, y la de Mentesa, al qual Lugar llama Montijar, y oy se dize La Guardia" (Catálogo de los Obispos de las Iglesias Catedrales de la Diócesis de Jaén y Annales Eclesiásticos deste Obispado. Edición facsímil, 1991, p.150). También A. Marcos Burriel, en sus Memorias para la vida del Santo rey Don Fernando III (Reedición facsímil de El Albir. Barcelona, 1974, p. 92), señala que: "Después de conquistar Arjona á los dias precisos para descanso del exército, y para la providencia en la nueva villa, se partió el Rey, y con poco trabajo[...], reduxo á su obediencia á Pigalajar, Bexix, Montijar, que es hoy la Guardia, Cazalla y Escarena". Más recientemente, F. J. Aguirre Sadaba; Ma C. Jiménez Mata (I979, pp. 232-233), y M. Jiménez Sánchez; T. Quesada Quesada (1992, p. 7I), han propuesto también esta identificación.
} 
medios y pequeños, y de arrendatarios libres, que constituiría la mayoría de la población. No se trata de un sistema igualitario, pero tampoco, por el momento, de un sistema totalmente señorial.

Las ventajas que se ofrecían a estos nuevos pobladores estaban contenidas bien en los fueros, bien en las cartas de repoblación, y por lo general suponían la entrega de lotes de tierra y vivienda, indicándose sus derechos, así como las cargas en renta o de otro tipo que debían satisfacer.

La organización administrativa y jurídica del Reino de Castilla en estos siglos se define por la multiplicidad de jurisdicciones. Por ello cada concejo, tenía su propio Fuero, el conjunto de leyes y normas específicas otorgadas por el rey, que enumeraban los derechos y obligaciones de los habitantes, grado de libertad para legislar otras normas específicas, etc. A su vez, podía otorgarse a una población un Fuero que ya tenía otra población, pero introduciendo variantes que dan lugar a las familias de fueros.

En los primeros años de la conquista del Alto Guadalquivir Fernando III otorgó el Fuero de Cuenca a las ciudades de Úbeda y Baeza y a la villa de Iznatoraf. Pero a partir de la segunda mitad de siglo, tanto él como sus sucesores prefirieron dotar a las poblaciones realengas conquistadas en la zona, con el Fuero de Toledo: Jaén, Arjona, Jódar, y ya en el siglo XIV, Alcalá La Real. En ninguna de ellas se ha conservado documentación relativa a sus normativas concejiles originarias ${ }^{15}$.

La diferencia fundamental que se establece en las ciudades andaluzas aforadas con una $u$ otra normativa, radica, pensamos, en el grado de autonomía y libertad que concedían las disposiciones derivadas de las coquenses respecto a las inspiradas en las de Toledo.

Tomando como ejemplo de las primeras el Fuero de Baeza ${ }^{16}$, vemos como contiene más de 900 disposiciones que regulan hasta el más mínimo detalle la vida concejil. Por el contrario, los fueros de la familia toledana son todos muchísimo más breves. Comenzando por el texto original: la $2^{\mathrm{a}}$ recopilación y confirmación del Fuero de Toledo realizada por Fernando III en 1222 -como hemos dicho más arriba, constituye su última y definitiva redacción- no supera los 40 capítulos. El Fuero de Córdoba, que salvo algunas pocas disposiciones, es una copia literal de este último, no supera los 60 capítu$\operatorname{los}^{17}$. El Fuero sevillano, es aún más breve.

Esta parquedad de los textos toledanos "....) Tenía un doble efecto en beneficio de la intervención real en los municipios en los que rigiera la citada normativa; permitía, por un lado, la posibilidad de creación de una nueva normativa que, deducida de las necesidades de cada localidad o comunidad, contribuyera a una mejor regulación institucional, y también hacía posible que la corona pudiera intervenir en la vida municipal, sobre todo y de manera más profunda ante las lagunas jurídicas de la norma foral" (CHAMOCHO CANTUDO, 1998: p. 90). Esta opinión ya fue defendida en su día por M. González, quien concluía que el fuero toledano que se aplicó en la mayor parte de las ciudades andaluzas "(...) No pasó de ser una normativa, prestigiosa sí, pero efímera, que pronto fue sustituida por los ordenamientos reales y por las ordenanzas municipales" (GONZÁLEZ JIMÉNEZ, 1980: p. 268).

\footnotetext{
15 En realidad, sabemos que a Jaén se le concedió el fuero toledano por noticias indirectas: en I284, Sancho IV le concede a la flamante Villa autónoma de Arjona el Fuero de Toledo. Cinco años después, los de Arjona solicitan un traslado de su fuero a los jiennenses, y estos le mandan una copia de la carta que ellos habían recibido a su vez de Don García Yváñez y Gonzalo Yváñez, alcaldes de Toledo, a quienes Alfonso X, en marzo de 1256 les había ordenado que remitieran al concejo de Jaén las mejoras que había introducido en su normativa municipal: "Sepades, que el Concejo de lahén me embiaron sus omes buenos et pidiéromme merced, que yo que les otorgase, que oviesen aquel asentamiento et todas las otras cosas que yo mejoré en el Fuero de Toledo quando hy fui, pues que ellos el fuero avíen de Toledo con las otras cosas, et tove a bien de ge lo otorgar et de ge lo dar" (Ximena Jurado, I665, p. 212).

16 Edición y estudio de J. Roudil, 1962.

17 A. Marcos Burriel, en sus Memorias para la vida del Santo rey Don Fernando III, incluye una copia del mismo (Edición anotada por Miguel de Manuel Rodríguez (1800). Reedición facsímil de El Albir. Barcelona, 1974, pp. 458-463).
} 
Respecto a las disposiciones forales que regulaban quienes debían de ser los individuos que dirigieran la administración y la justicia concejil en delegación del rey, se ha convertido en un lugar común la idea de que el Fuero de Cuenca y sus derivados posibilitaba el ascenso a estos puestos de los no nobles, mientras que los textos toledanos no preveían mecanismos especiales de ascenso social, favoreciendo por consiguiente la formación de oligarquías urbanas nobiliarias (QUESADA QUESADA, 1989: p. 50I). La comparación de los fueros andaluces de una u otra familia, nos hace pensar que esta creencia debe ser matizada.

Sin duda, los caballeros e hidalgos de los concejos regidos por el fuero toledano gozaban de enormes ventajas económicas estipuladas por dicha normativa, basadas sobre todo en el privilegio de la exención tributaria, ya que no debían de pagar el diezmo (o décima) ni por sus heredades ni por la producción que de ellas extrajeran, ni ningún otro tipo de gravámenes reales (GARCÍA GALLO, opus cit:: pp. 485 y s.). En el Fuero de Córdoba estas exenciones se confirman, aunque Fernando III negó a los caballeros cordobeses algunos de los privilegios de que gozaban los milites toledanos, como los derechos del almojarifazgo y el del mesón del trigo ${ }^{18}$. En el texto cordobés también se omite otro importante privilegio del que gozaban los toledanos, el que autorizaba a la libre construcción de molinos y pesqueras (GARCÍA GALLO, opus cit:: p. 402).

No obstante, el Fuero de Córdoba también contemplaba exenciones para los no nobles, y posibilidad de romper la estratigrafía estamental a través de la riqueza: "Si alguno de los peones quisiere ser caballero, y pudiere enriquecer, éntre en los fueros y las costumbres de los caballeros: sobre todo esto sus fijos, é los herederos dellos ayan sus heredades firmes establecidas para siempre, é vendan, é compren el uno del otro, é den á quien se quisieren, é cada uno faga su voluntat en su heredat. [...] Mando, é otorgo, que los peones de Córdoba, é de su término, nunca den diezmo al rey" (MARCOS BURRIEL, 1800: p. 459 y 461). En el texto cordobés, además, se ampliaba a todos los vecinos y moradores de la Ciudad y su Tierra una exención que en Toledo sólo gozaban los caballeros, la de no pagar portazgo por la caza en sus montes y la pesca en sus ríos.

Esta "generosidad" con los individuos no dotados de la ventaja del linaje de sangre, se refleja también en las disposiciones sobre los cargos públicos del Concejo. Veamos primero como se establecía el sistema de elección de autoridades concejiles en Baeza, cuyo fuero, recordemos, pertenecía a la familia coquense, y por lo tanto era supuestamente más liberal, para luego compararlo con las disposiciones vigentes en Córdoba y Jaén, derivadas, insistimos del Fuero Toledano, y por lo tanto, teóricamente más oligárquicas.

En Baeza, todos los cargos públicos (juez, alcaldes, escribano, andadores etc.), tenían una duración anual. Cada año, el domingo siguiente a la fiesta de San Miguel, los vecinos de cada collación de la ciudad debían de elegir un juez y un alcalde, entre los vecinos que tuvieran casa en la ciudad desde hacía más de un año, y que poseyeran caballo ${ }^{19}$.

Por lo que se refiere a Córdoba, el rey dispuso: "Dó, é otorgo por fuero al pueblo de Córdoba, que ayan jueces, alcaldes, é mayordomo, é escribano, é sean mudados cada anno, é los alcal-

\footnotetext{
18 "Yo rey don Fernando dó á todos los caballeros de Córdoba todas las franquezas é privilejos que han los caballeros de Toledo, salvo los derechos del Almojarifazgo del rey, é el mesón del trigo [...]. Otorgo é mando á los caballeros de Córdoba, que ayan omecillo é caloña de su paniaguado si con él morare, é de su quintero si labrare heredat de caballero, é de su alogado si matare.Otrosí de su solariego dé pecho" (MARCOS BURRIEL, I800, p. 463).

19 "Mando aun que el primer domingo despues de la festa de Sanct Migael, el conceio pongan iuez e alcaldes e escriuano e andadores, sayon e almutaçaf cada un anno por fuero. Cada un anno dezimos por esto, que ninguno non deue tener officio de conceio nin portiello si non por un anno, fuera end que el conceio aclamen por él. E en aquél domingo que auemos dicho, la collation ond el iudgado de aquel anno fuere a seer, den iuez sabidor que entienda departir la uerdat de la metira, e el derecho del tuerto, e de buen pienso, e que aya casa en la uilla e cauallo. Ca todo aquel que casa poblada non tuujere en la villa e cauallo de un anno ante, non sea iuez. [...] Otro si, cada una collation dé su alcalde, en aquel dia atal qual dissiemos del iuez, que aya cauallo e casa poblada en la uilla de un anno ante" (ROUDIL, 1962, pp. 134 y s.).
} 
des que sean quatro, é la collacion en que la elección del alcaldía cayere, todos los de la collacion escojan quatro omes buenos, que sean derechos á estos portillos; é estos quatro [...] de la abandicha collacion echen suerte qual dellos sea en el portillo, é aquel sobre quien cayere la suerte sea en el portillo fasta el anno, que es puesto de sant Joan fasta sant Joan. [...] é si por aventura aquellos de la collacion non concordaren escogiendo estos quatro omes buenos de las collaciones, que debe escoger, estos quatro embien al rey sus buenos omes, é como él mandare sea así" (BURRIEL, opus cit: p. 458).

Aunque de Jaén, como ya dijimos, no se conserva ningún documento que recoja su normativa originaria, afortunadamente sí que existen, de los reyes de la dinastía Trastámara, cartas de confirmación de privilegios otorgados por monarcas anteriores. Para la comparación que estamos realizando, el más interesante es la otorgada por Enrique II en 1375, tras la devastación e incendio sufrido por la ciudad de Jaén en 1368 en el curso de la guerra con el rey Pedro, durante los cuales fueron destruidos los documentos concejiles. En dicho documento se puede leer que la ciudad de Jaén tenía "de cada año quatro alcaldías, e el alguaziladgo, e los otros ofiçios que eran diez jurados e las escrivanias e personerias del conçejo, los quales ofiçios [...] echavan suertes cada año los ommes bonos, aquellos que mantenian cavallos e armas, vezinos de la dicha çibdad, aquellos que eran pertenesçientes a las escrivanias públicas del conçejo de la dicha çibdad que las davan graçiosamente a los fijos de los vezinos, aquellos que eran pertenesçientes para ello" 20.

Como vemos, en ninguna de las tres normativas concejiles expuesta se excluye del gobierno ciudadano a los no nobles. En la de Córdoba, ni siquiera existe la exigencia, explícita en la de Baeza y Jaén, de que los omes buenos escogidos tuvieran que mantener caballo o armas. Cambia el sistema de adquisición de los diferentes cargos públicos, que en Córdoba y Baeza es por elección, rotándose las collaciones, y en Jaén es por sorteo, y la clara injerencia real en el de Córdoba, que se reserva la elección final de cargos cuando hubiera disputas o desacuerdos.

Así pues, debemos rechazar la idea de que, en el siglo XIII, las normas forales otorgadas a las diferentes ciudades conquistadas favorecieran la creación de oligarquías exclusivamente en función del linaje. Todas ellas, fueran de la familia coquense o toledana, responderán, más bien, a las exigencias de atraer a estos territorios fronterizos no sólo a la hidalguía o nobleza castellana, sino también a individuos que aun no perteneciendo al estamento aristocrático, tuvieran capacidad de ayudar en su defensa -al poder mantener caballos y armamento, y por lo tanto, acomodados desde el punto de vista económico-, y que, una vez instalados, encontraran las suficientes ventajas $y$ beneficios como para que mereciera la pena quedarse: caballeros "villanos" o "cuantiosos", a quienes, a través de las disposiciones de los diferentes fueros, se les permitía alcanzar un elevado status, con los derechos y privilegios de los hidalgos, en función de su valía y utilidad militar.

A este respecto, las disposiciones dadas por Fernando III a la ciudad de Jaén son ejemplificadoras: "E otrosi que avie más Jahen de previllejo que todos los que en Jahen toviesen e mantoviesen cavallos e armas que oviesen las honrras e libertades que avian los caballeros de Toledo e vezinos, e mejorías de Cordova" (CHAMOCHO CANTUDO, 1997: Apéndice documental, p. 310).

Fernando III también incluyó en sus mercedes y privilegios a los individuos que vinieron a repoblar las tierras jiennenses, y que no pertenecían a la elite de los caballeros -hidalgos o villanos-, favoreciendo sobre todo la puesta en cultivo de los campos y la cría de ganado.

20 Confirmaciones de privilegios a la ciudad de Jaén por Enrique II, Enrique III e Isabel I de Castilla. Todas son copias autorizadas hechas en Jaén a 17 de enero de 1504. AGS. Patronato Real, leg. 58, fol 74. (Edición y estudio de CHAMOCHO CANTUDO, I997, Apéndice documental, p. 310). 
Probablemente de su mandato procede el privilegio por el cual "todos los vezinos y moradores que fuesen francos e quitos de pagar portadgo e almoxarifadgo e de todas las otras cosas que bendiesen e llebasen que fuesen de labrança de sus heredades e de criança de sus ganados" (Ibídem, p. 310), pero, el privilegio más importante del que gozarán los jiennenses respecto a una actividad económica será el que hacía que todo su territorio por quanto esta muy çerca de los moros (Ibídem, p. 31 I) estuviera libre de cañadas, sin servidumbre de paso, por lo tanto, para ganados foráneos, e independiente de la jurisdicción del juez de cañadas y, más tarde, de la Mesta.

\section{LA DIÓCESIS EPISCOPAL}

Una jurisdicción diferente a la real y concejil y en gran medida superpuesta a ella, será la episcopal. En principio, la sede del obispado de estas tierras no estará en Jaén, sino que la ciudad escogida será Baeza. Esta ciudad había sido sede episcopal en época visigoda, estando bajo la jurisdicción de la sede metropolitana de Toledo, y su obispo, bajo la autoridad del primado toledano, por lo que su restauración, tras su conquista en 1226, entroncaba perfectamente con la ideología imperante de reconquista con la que los castellanos avalaban su expansión a costa de los musulmanes.

Sin embargo, tras la conquista de Jaén, Fernando III decide solicitar al papa el traslado de la sede del obispado de Baeza a Jaén. El pontífice accedió a la petición real, y aunque no se conoce la fecha exacta en la que se efectuó el traslado, este debió concretarse entre el 3 de septiembre de 1248, fecha en que aparece por última vez en la documentación fray Domingo como obispo de Baeza, y el 31 de marzo de 1249, en que es nombrado D. Pedro Martínez electo de Jaén, aunque nunca llegó a ocupar la silla episcopal, al morir por el camino (SEGURA MORENO, 1976: p. 44).

Lógicamente, ante el enorme perjuicio que esta modificación suponía para sus intereses, los eclesiásticos de Baeza protestarían enérgicamente ante el papa, consiguiendo, en mayo de 1249, que Inocencio IV instara al obispo de Jaén a que "en la Iglesia de Baeza hagas que bajo nuestra autoridad permanezcan seis $u$ ocho canónigos" (Ibídem, p. 7I). A partir de este momento, la diócesis de Jaén contaría con dos iglesias catedrales.

El interrogante histórico a dilucidar es por qué el rey solicitó este cambio de sede. Pensamos que lo hizo por dos razones fundamentales:

- La primera, de orden, digamos, estratégicopolítico: Seguramente lo hizo con el fin de garantizar la posesión de este importantísimo bastión frente al naciente Reino Nazarí. Efectivamente, uno de los principales inconvenientes para la defensa de la plaza jiennense era su posición adelantada y excéntrica respecto al resto de las conquistas realengas en este sector. Parece, pues, lógico pensar que el ubicar en ella una institución tan importante y de tan alto valor simbólico como la sede del obispado, reforzaría su posición, al involucrar mucho más directamente en su defensa a la Iglesia, y a las fuerzas militares que esta última podía desplegar. A su favor, Jaén contaba con que era "...Villa real et de grant pueblo et bien enfortalesçida et bien escastellada de muy fuerte et de muy tendida çerca et bien asentada et de muchas et muy fuertes torres, et de muchas et buenas aguas dentro de la villa, et abondada de todos abondamientos que a noble et a rica villa convien aver" (Primera Crónica General de España, cap. 1070).

- La segunda razón entraría de lleno en el ámbito de las complejas relaciones que mantenían la monarquía y la Iglesia: Con el traslado, Jaén detentaría su jurisdicción eclesiástica sobre las antiguas diócesis visigóticas de Mentesa (la Guardia), Tucci (Martos) y Baeza, a pesar de que ella nunca fue sede episcopal durante el período visigodo. Precisamente esta última característica suponía una ventaja nada despreciable de cara a las posibles reivindicaciones del Arzobispo de Toledo, que ya habían motivado multitud de problemas cuando el obispado se dirigía desde Baeza. 
Efectivamente, Jiménez de Rada no podía ejercer sobre Jaén la facultad que en 1234 le había otorgado el papa Gregorio IX de promover hombres idóneos para la función episcopal en aquellas ciudades de su provincia eclesiástica que antiguamente habían sido sedes episcopales, y que ahora comenzaban a ser aptas para ello (SANZ SANCHO, 1995: p. 28), por lo que se eludía hábilmente el posible establecimiento de lazos de dependencia personal entre los obispos giennenses y el metropolitano de Toledo.

Si bien desde su restauración Fernando III otorgará diversas rentas y tierras al obispado de Baeza, éstas estarán circunscritas sobre todo al entorno de Úbeda y Baeza, no concediéndole nada, una vez que se conquista la ciudad, en el término de Jaén. Esta política real sólo cambiará a partir, concretamente, del 14 de marzo de 1248, en que le dona, al todavía obispado de Baeza "el diezmo del almoxerifatgo de Jahen (e)t del MeSon. assi como lo ha el Arçob(is)po de Toledo (e)t aSSi como dize la carta del fuero q(ue) yo di a Jahen (e)t dargelo bie(n) toda uja de guisa q(ue) lo aya bien parado (e)t no(n) fagades ende al Si no(n) peSar mje" (SEGURA MORENO, 1976: p. 188). Esta donación debe estar, seguramente, relacionada con la solicitud de traslado desde Baeza a Jaén de la sede episcopal, en la que el monarca castellano prometería al papa dotar abundantemente a la segunda como, de hecho, ya lo estaba haciendo.

En el mismo documento de 31 de marzo de 1249 en el que confirma a Don Pedro Martínez como electo de la Iglesia de Jaén, el rey incluye la donación de "mil monedas alfonsinas de oro de mis rentas que tengo en tierras del rey de Granada y esto lo hago por el especial afecto, que tengo a la Iglesia de Jaén y porque quiero beneficiarios. [...] Y que cuando Yo, ya a vosotros o a la antedicha Iglesia os entregare alguna propiedad o herencia, que haya de valer mil o más monedas de oro, que os gastéis las dichas monedas de oro" (Ibídem, p. II6).

No debió parecerle suficiente dote al pontífice (o al obispo jiennense, que haría llegar sus quejas a Roma), y el 6 de abril de I25। Ino- cencio IV envía a Fernando III una carta en la que el papa le recordaba que, en atención a sus súplicas, había accedido a la erección en Jaén de una iglesia catedral, dotándola de su correspondiente obispo, por lo que ahora le instaba a que cumpliera sus promesas de equipar generosamente la nueva sede, de acuerdo con las cláusulas de solicitud de traslado (RODRÍGUEZ MOLINA, 1986: p. 18 y nota n ${ }^{\circ} 20$ ). Es probable que, tras este amable recordatorio, el rey decidiera concederle en señorío al flamante obispado jiennense el castillo de Cárchel, ubicado en el sector fronterizo más meridional del Concejo jiennense.

A partir de este momento y en adelante, los reyes hicieron continuas donaciones al obispado, a las que hay que sumar las efectuadas por particulares y las compras que realizaron los obispos y el cabildo catedralicio, todo lo cual permitió a esta institución, como demostró el profesor Rodríguez Molina, constituir un inmenso patrimonio, la mayor parte de él concentrado en el Concejo de Jaén, del cual se constituyó en el primer gran propietario de tierras y rentas, ejerciendo una gran influencia política, social y económica.

\section{LOS MUDÉJARES}

En cuanto a los mudéjares, la población musulmana vencida, lo único que existe es el silencio. No se mencionan en las fuentes históricas conservadas, y por lo tanto, tampoco en los estudios realizados a partir de ellos. Se supone que, como ocurrió en otras ciudades conquistadas, como Córdoba, Arjona o Sevilla en las que había mediado capitulación, los musulmanes salieron libres de la ciudad de Jaén, llevando consigo sus propiedades muebles y semovientes, perdiendo sus bienes inmuebles (casas y tierras), que, como hemos visto, serían objeto de donaciones y reparto entre conquistadores y pobladores, abandonando de inmediato la localidad, protegidos por salvoconductos firmados por el rey, con destino a territorio musulmán (GONZÁLEZ JIMÉNEZ, 1988: p. 27).

Pero ¿Qué ocurrió en el amplio alfoz que controlaba Jaén? Las prospecciones arqueoló- 
gicas realizadas hasta la fecha nos informan que, al menos en la última fase almohade, hay un incremento, en la zona, de asentamientos de nueva creación, al igual que una ampliación de los ya existentes y la construcción o refuerzo de fortificaciones destinadas, a juzgar por su tipología, al refugio de los campesinos y sus rebaños. Sin duda, estos nuevos contingentes de población musulmana llegaban del norte del Guadalquivir, área que, tras la derrota de las Navas, en 1212, había dejado de ser segura.

No obstante, cuando, a partir de finales de la $2^{\text {a }}$ década del siglo XIII Jaén se convierte en objetivo prioritario de la conquista castellana, estos asentamientos rurales debieron de comenzar a ser abandonados, ya que la estrategia cristiana se basaba en la eliminación de las fuentes de aprovisionamiento de la ciudad de Jaén con la destrucción y tala sistemática de su alfoz. Es probable, sin embargo, que en las aldeas se dieran casos de permanencia, iniciándose así un período, breve, de coexistencia de dos sociedades: una cristiana feudal, instalada en las ciudades y recintos fortificados; y otra, mudéjar y rural, de comunidades campesinas (QUESADA QUESADA, 1989: p. 498).

Aunque, en el alfoz jiennense parece que, en verdad, si este período de coexistencia existió, fue realmente corto. Tras la conquista de la ciudad, y en un primer momento, los castellanos siguieron las pautas de asentamiento ya ensayadas en otras zonas, ocupando la ciudad y los recintos fortificados que les garantizaban el control de los pasos y de las vías de comunicación, concentrándose la población campesina vencida que no había huido, en las aldeas más importantes que, en un principio, los cristianos se contentarían con dominar a distancia, y siendo expulsada de los núcleos rurales menores; al menos, así parece indicarlo, como ahora veremos, la temprana castellanización de la toponimia rural.

\section{PRIMERA DEFINICION DE LOS LIMITES TERRITORIALES DEL CONCEJO DE JAÉN}

Por el Sur el Concejo limitaba con el reino nazarí, el cual tenía como puntos fuertes de la frontera los castillos de Arenas y Cambil, junto a los que posiblemente subsistieron inicialmente poblaciones, al menos en el segundo caso. Por parte castellana, en esta zona se dominaba una serie de castillos controlando todos los caminos a Jaén: en la margen derecha del Guadalbullón, Pegalajar y Bexix; en la margen izquierda, Cárchel y Cazalla y más al noroeste, controlando el paso por el estrecho valle del río Quiebrajano, el castillo de Otiñar.

Cuando se conquistó la ciudad de Jaén y se estructuró un concejo realengo en torno a ella, ya existía, cubriendo más de la mitad de su flanco oeste, el Señorío de la Orden Militar de Calatrava, que con su centro neurálgico ubicado en la encomienda de Martos, dominaba las localidades de Porcuna, Lopera, Jamilena, La Higuera (hoy Higuera de Calatrava) y Alcaudete, incluyendo los castillos de Locubín, Susana y Viboras, sirviendo de barrera fortificada frente a las incursiones de los nazaríes por Alcalá de Benzayde (Alcalá La Real).

Conforme se definía el alfoz jiennense en este sector, surgieron los primeros problemas de vecindad, que el rey Fernando tuvo que resolver en la primavera de $\mid 251$, amojonando personalmente el límite entre el concejo realengo y el señorío calatravo, amojonamiento del que ha quedado constancia gracias a la confirmación que hizo del mismo Alfonso $X$ el 22 de abril de 1254 21. La información geográfica y toponímica que aporta este documento ayudó a J.C. Castillo Armenteros, J.C. Lara Jiménez y J.L. Castillo Armenteros, en su intento de reconstrucción del proceso de amojonamiento, en un trabajo de prospección arqueológica superficial de la zona (opus cit., pp. 369-375) (FIGURA 4).

\footnotetext{
21 La Divisio terminorum inter civitatem de Jaen, \& villas de Martos, \& Locovin à Rege Domino Ferdinando III. facta ac etiam permutatio de Susanna, Zafra, \& alijs juribus in Arjona, pro Zambra, à Rege Domino Ildefonso X. confirmantur (ORTEGA Y COTES Y ORTEGA ZÚÑ̃IGA y ARANDA (eds.), 1762: Bulario de la Orden Militar de Calatrava. Reedición El Albir, I98I, Scriptura XVIII, pp. 94-97).
} 
Fernando III inició la delimitación partiendo del punto más meridional de la franja territorial en conflicto, situando el primer mojón en las estribaciones de la Sierra de Alta que se eleva a 10 kilómetros al nordeste de Alcalá La Real, concretamente en un cerro desde el cual se divisaba esta localidad nazarí.

A partir de este punto, la delimitación sigue en línea recta, recorriendo transversalmente la Sierra de La Pandera, hasta llegar al pie de monte de la Sierra de la Grana, cerca de Torredelcampo. En definitiva, todo el Frente Externo de las Cordilleras Béticas quedaba en poder del Concejo de Jaén.

El único punto conflictivo en este sector serrano será el castillo de Susana o Susaña, que, perteneciendo a la Orden, quedaba incluido en territorio realengo; efectivamente, el segundo mojón asentado por el rey estaba "en la sierra mas alta, que està entre Susanna, è Locovin, fata un oteruelo que està en cabo de la sierra". Para resolver el problema, el monarca incluyó este castillo en un acuerdo de permuta con los calatravos, que también quedó establecido en el documento, por el cual les donaba Zambra "con todos sus terminos, è con sus entradas, è con sus salidas, è con montes, è con rios, è con fuentes, è con pastos, è con logares yermos, è con poblados, assi como nunqua mejores los ovo en tiempo de Moros", a cambio de que la Orden entregase a Fernando III, además de Susana, "...Zafra, è veinte yugadas de bues, que haviedes vos el Maestre de Calatrava, è la Orden en Arjona, è por el quinto de la renda que haviades en Arjona, que me diestes de vuestra bona voluntad, è sin premia ninguna" (ORTEGA Y COTES Y ORTEGA ZÚÑIGA y ARANDA (eds.), 1762: Scriptura XVIII, pp. 95-96).

En este proceso de amojonamiento de las sierras meridionales llama la atención el completo desconocimiento de la toponimia local del que hacen gala los castellanos. No se cita por su nombre árabe ni siquiera uno de los hitos geográicos -la mayoría cerros u oteros- que servirán de base para los mojones, utilizándose referencias geográficas y alusiones a acontecimientos tenidos lugar en sus cercanías ${ }^{22}$.

Sin duda, como ya pusieron de manifiesto M. Jiménez y Tomás Quesada refiriéndose a Sierra Mágina (opus cit., 1992, pp. 51-80), el conocimiento que los castellanos tenían de las tierras que conquistaban era muy desigual, siendo mayor sobre las grandes ciudades musulmanas y sus territorios, con las que habían tenido contactos asiduos desde época califal y taifa, y mucho menor en las zonas alejadas de ellas y de las grandes vías de comunicación: "En este sentido, las zonas montañosas del Sistema Bético debieron ser unas grandes desconocidas para los cristianos, teniendo en cuenta, además, que fue en ellas donde se frenó el impulso expansivo que en doscientos años había llevado a los reinos cristianos desde el Sistema Central al Sistema Bético" (Ibídem, p. 52).

A parte de esta falta de conocimiento directo sobre el territorio que evidencian los castellanos, hay que señalar que, a diferencia de otras zonas geográficas, en este caso no se utilizaron a elementos de la población musulmana sometida para ayudar en el amojonamiento; en el documento de $125 \mid$ el rey cita a sus acompañantes, y entre ellos no se hace mención a ningún mudéjar: "andando conmigo el Maestre de Calatrava, è sus Freyres, è omes bonos por el Concejo de Jaen" (ORTEGA Y COTES Y ORTEGA ZÚÑIIGA y ARANDA (eds.), I762: Scriptura XVIII, p. 95).

Podemos conjeturar que estas sierras, cuyos puntos fortificados habían sido conquistados uno a uno desde finales de la segunda década del siglo XIII, se hubieran despoblado bastante antes de la caída de Jaén de 1246, y que, tras la capitulación de ésta, los pactos por los cuales la población musulmana fue expulsada se cumplieran a rajatabla, por lo que, sencilla-

22 Tales como "...et assi como uiene por somo del Alcor fata el otero gordo sobre las cuebas o desbarataron à Pascual Porquerizo, es el otro fito: et assi como và en derecho fasta la cabeza o fueron desbaratados los Gazules, en somo del otero, es el otro fito: et assi como và el Alcor arriba fata el portiello que descende un senderuelo pequenno..." (Ibídem, p. 95). 
mente, no había nadie con conocimiento del terreno en quien los castellanos pudieran apoyarse para la delimitación.

La temprana "castellanización" del territorio jiennense parece también evidente cuando, en el proceso de amojonamiento, se abandona el sector serrano para adentrarse en la Campiña. En ella, no se utilizan hitos geográficos para la delimitación, los mojones son ubicados sistemáticamente en, o cerca de, lugares fortificados, concretamente en torres, que son reconocidas por el nombre de su poseedor o constructor, de claro origen castellano, tales como "...et assi como descende al atalaya nueva, que fizo Don Esidro[..], que essa Torre es el otro fito [...], et assi como và el fito, que fizo el rey, que està sobre la Torre del Carnicero, è và al otro fito, que es en la pennuela, que està cabo del Pozo entre la Torre de Gil Alfonso, è la Torre de Hospital, è va al otro fito [...], que està entre la Torre de Gil Alfonso, è el Villar de Don Pardo..." (Ibídem, p. 95).

A diferencia del sector montañoso fronterizo -que, en función de la lectura de este documento de I25 I, aparece como un amplio espacio vacío, sin núcleos de población estables, en la Campiña, es evidente que el proceso repoblador y de repartimiento ha comenzado: los castellanos controlan el territorio y principian la explotación de sus recursos. La hegemonía del castellano en la toponimia de los pequeños centros rurales, a tan sólo cinco años de la conquista de la ciudad de Jaén, parece que nos informa de que, este proceso de asentamiento castellano, se realizó sobre un territorio en su mayoría abandonado por la población campesina vencida, la única que podía dejar constancia del nombre de sus tierras y poblados.

Una excepción a esta generalidad, nos la da también el documento: Casi al final del amojonamiento, aparece citada, como perteneciente al señorío calatravo, la localidad de las Torres de Avenzala, topónimo de evidente origen árabe. En la delimitación entre esta población y el Villar de Don Pardo, Fernando III actúa con gran minuciosidad, prueba de que, seguramente, los vecinos de ambos lugares habrían protagonizado más de un enfrentamiento por cuestión de sus términos ${ }^{23}$.

El último mojón que partía tierras calatravas y tierras jiennenses se colocó en el Arroyo Salado de Los Villares. A partir de aquí, y hasta el Guadalquivir, los límites son considerablemente más confusos. Por un lado le pertenecían las aldeas de Fuente de la Figuera (hoy La Higuera) y Villanueva (hoy Villanueva de la Reina), esta última ubicada junto a la orilla izquierda del río Guadalquivir.

Por lo que se refiere a Arjona, la situación jurídica de esta localidad bajo Fernando III no está clara, aunque lo más probable es que fuera Concejo de Realengo; hay dos "pruebas positivas". La primera es la mención a Arjona en el mismo plano que Jaén cuando Fernando III encomienda la defensa del territorio de ambas a la Orden de Calatrava a cambio de las concesiones que está efectuando (GONZÁLEZ JIMÉNEZ, | 1991: documento $n^{\circ}$ |30); la segunda es un comentario de Ximena Jurado (opus cit., I665, p. 190) sobre el apoyo que el Concejo de Arjona prestó a Fernando III en la toma de Sevilla. Hay también otras "pruebas negativas", es decir, de que no pertenecía a ninguna de las otras grandes entidades de la zona: en primer lugar, no figura entre las localidades cedidas a la Orden de Calatrava recogidas en el documento de 125I, es más, como hemos visto, el rey "rescata" el porcentaje de rentas y la gran propiedad (20 yugadas de tierra corresponden a más de 350 hectáreas) que habían conseguido los calatravos en Arjona; en segundo lugar, las reformas que efectuará Alfonso $X$ en 1254 , indican que no pertenecía ni a Andújar ni a Jaén (Ibídem: documento $n^{\circ}|| 2$ ).

\footnotetext{
23 "...et de este fito del era assi como và à moion cubierto al fito, que es entre las Torres de Avenzala, è el Villar de Don Pardo, è este fito fiz yo fincar en tal logar, que mandè partir el termino, que de la primera casa del Villar de Don Pardo contra las Torres de Avenzala, et de la primera casa de las Torres de Avenzala contra el Villar de Don Pardo mandèlo partir por soga, è mandè que fincassen las dos partes del termino de las Torres de Avenzala, è la tercera al Villar de Don Pardo, è fiz ì poner el fito sobredicho" (Ibídem, p. 95).
} 
Por el Norte, el río Guadalquivir servía de división entre el Concejo de Andújar y el de Jaén, y, remontando su curso, entre las tierras de esta última localidad y el Concejo de Baeza (FIGURA 5). No obstante, volvemos a encontrar, en esta primera época, gran indefinición en los límites cuando intentamos fijar el flanco oriental. Para ello, sólo contamos con el documento de 19 de mayo de 1231, en el que Fernando III delimita los términos de Baeza ${ }^{24}$. Según el documento, los dos concejos comenzarían su vecindad el la desembocadura del río Rumblar (el Ferrumbral del documento) en el Guadalquivir, a un kilómetro y medio al noroeste de Espeluy, y continuaría hacia el Este, aguas arriba de este último río, hasta llegar a donde Torres dividía términos con Jaén.

Sin duda, Torres debe ser identificada con la actual localidad del mismo nombre, situada en el pie de monte septentrional de Sierra Mágina, pero el documento no da detalles sobre el lugar donde se produce el contacto entre ambos términos. Lo que parece lógico si tenemos en cuenta que el documento fue expedido 15 años antes de que se verificara la conquista de Jaén. Pero, por lo que sabemos, la situación quedó igualmente ambigua tras la creación del Concejo Jiennense, ya que, un siglo más tarde, y amparándose precisamente en esta vaguedad, los jiennenses se apoderan de parte del término baezano en este sector oriental, provocando un pleito cuyo resultado será la fijación precisa del límite entre los dos territorios realengos ${ }^{25}$.

Al parecer, el límite entre los dos concejos lo marcaba el Arroyo Vil, y los de Jaén lo habían traspasado en su curso medio, apropiándose de una franja de terreno situado al este de su curso, en la que se incluían varias fuentes y la torre de Recena, ubicada en la margen izquierda del río Torres. Todo este terreno, junto al que se encontraba dentro de los límites "legales" del Concejo de Jaén, formaría parte de la Dehesa del Riez, que además no estaba destinada a ser de uso común para todos los vecinos de Jaén, sino que formaría parte de los bienes propios del concejo, como se induce del hecho de que Jaén, incluso durante el tiempo que duró el pleito, la tenía arrendada (Colección Diplomática de Baeza, 1983: doc. n 42, p. I I6) (FIGURA 6).

La parte más conflictiva del límite estaba al sur, en los alrededores de la Fuente de Don Pardo, por lo que el obispo de Jaén Don Juan, mediador en el conflicto enviado por el rey, decidió que allí se estableciera una comunidad de pastos entre ambos concejos "para paçer e bever e cortar e caçar", mientras que, de la Fuente Don Pardo, hacia el norte, siguiendo el Arroyo Vil hasta su desembocadura en el Guadalquivir, "ende parte de Jahen es de Jahen e de parte de Baeça es de Baeça" (Ibídem, p. 217).

\section{EL POBLAMIENTO EN EL SIGLO XIII: PERMANENCIA DE LOS ASENTAMIENTOS Y CAMBIOS FUNCIONALES}

Dos son los tipos de asentamiento rural que impondrán los castellanos en el Concejo de Jaén: aldeas y cortijos.

Las aldeas de las que tenemos constancia de su existencia desde la conquista castellana son Villardompardo, Torredelcampo, El Berrueco, Mengibar y Pegalajar. A las que podríamos

\footnotetext{
24 "...dono itaque uobis et concedo terminos per loca inferius nominata uidelicet: per portum de Muradal sicut aque corrunt uersus Baeciam et quomodo uadit summitatem serre usque ad directum ubi caedit Ferrumbral in Guadalquiuir et de Ferrumbral per Guadalquiuir ad sursum usque ad Torres sicut diuidit terminum cum Jahen et do uobis Torres cum suo termino; et deinde quomodo uadit per summitatem serre de Bedmar et de Xodar sicut aque currunt usque Baeciam et de serra de Xodar quomodo descendit directe ad Xandoliellam et Xandoliellam cum suo termino sicut tenet usque Guadalqueuir..." (HIGUERAS MALDONADO, 1974, pp. 16 y s).

25 Pleito que el Concejo de Baeza interpuso al de Jaén ante Alfonso Xl a mediados de I338, porque los de Jaén, en el proceso de amojonamiento de una gran dehesa en la Campiña Oriental, habían invadido "con su pendon armados e assonados" el término de Baeza, llevándose por la fuerza el ganado que encontraron, por lo que los baezanos "reçebieron grant agravio". El rey envió como mediador en el conflicto a Don Juan, obispo de Jaén, quien tuvo que esclarecer los límites entre ambos concejos. (Colección Diplomática de Baeza, 1983, doc. $n^{\circ} 42$ ).
} 
unir Fuente del Rey, si aceptamos su identificación con la localidad denominada Torre de Fuentes en el diploma de 1246, antes mencionado. A este primer grupo de aldeas, consideramos que podemos unir, como existentes desde la segunda mitad del siglo XIII los núcleos de población calificadas como parroquias rurales dependientes del Arciprestazgo de Jaén en I3II: Cazalilla, Villargordo, Villar de Cuevas, Garcíez y Olvidada, junto a los asentamientos menores de Fuentetétar (unido a Mengibar), Aldehuela y Torre de Lope Fernández (que juntos formaban una parroquia independiente).

En primer lugar, porque, con toda probabilidad, la organización parroquial del espacio rural del Obispado de Jaén se realizó, en la segunda mitad del siglo XIII, a partir de núcleos de población, que en esos momentos se consideraban estables, lo que explicaría que existieran términos parroquiales que englobaban más de un núcleo de población, ya que así se garantizaba un determinado número de feligreses, como es el caso, de Mengibar y el cercano castillo de Fuentetétar, o el de La Aldehuela, que lo hacía junto a la Torre de Lope Fernández. En segundo lugar, porque en todos ellos, si exceptuamos Cazalilla, Villargordo y Olvidada, las evidencias arqueológicas encontradas durante las prospecciones apuntan a su existencia ya desde época almohade. Aunque la identificación que realizan F. J. Aguirre y $M^{a}$ C. Jiménez de Cazalilla con la Qasțalla de las fuentes árabes, nos la señalarían como un centro de población importante anterior a la conquista castellana ${ }^{26}$ (FIGURA 7).

Poco podemos decir sobre la estructura interna de estas aldeas, la falta de excavaciones arqueológicas y el hecho de que en las escasas menciones que encontramos sobre ellas en las fuentes escritas, el interés se centre sobre todo en las fortificaciones que algunas tenían, hace, por ahora, imposible definir cuales serían sus elementos "urbanísticos" y constructivos definitorios, a parte, naturalmente, de la iglesia. Pero sin duda, tras la conquista, y al igual que ocurrió en la propia ciudad de Jaén, donde la concepción del espacio urbano cambió radicalmente, tras su rápida división en collaciones, en las aldeas se realizó un apiñamiento de los solares en torno a la iglesia parroquial creada, y el recinto defensivo fue drásticamente reducido, apareciendo el típico castillo de reducidas dimensiones y con torre del homenaje, habilitado sólo para las tropas y el alcaide. Un ejemplo significativo es el del El Berrueco (FIGURA 8).

El original recinto fortificado, datado en época almohade, aprovecha un largo afloramiento rocoso de forma aproximadamente rectangular, que fue utilizado con toda probabilidad como albacar o zona reservada para estabular ganado durante los asedios. Sus lienzos no están defendidos por torres, sino que su trazado quebrado facilita la aparición de ángulos que rompen la horizontalidad del paramento, permitiendo una mayor estabilidad $y$ defensa. A parte de esta función, la ubicación de la fortificación fue elegida, seguramente, con el objetivo de controlar el importante cruce de caminos situado en este asentamiento, en unos momentos en los que la presión cristiana sobre la campiña se hacía cada vez más intensa (SALVATIERRA CUENCA, ed., 1995: p. 92 y ss.)

Tras la conquista cristiana, la importancia estratégica del lugar se mantuvo, configurándose una aldea en torno al castillo, el cual fue remodelado por los cristianos. Se configuró así una nueva estructura, pensada por otra formación social y destinada a otros usos, que es la que se ha mantenido hasta nuestros días.

\footnotetext{
26 Según estos autores, Cazalilla pueda ser identificada con el Qasțalla citado por al-Muqaddasī en el siglo X, como uno de los 13 rustāa o distritos de Córdoba. La adscripción a Córdoba del rustāa o iqlīm de Qasțalla, y de otros próximos, como Arŷūna (Arjona), Jódar, Martos, Hišn Bulkūna (Porcuna), Wādi 'Abd Allāh y Qarsīs (Garcíez) sería equivocada, perteneciendo en este momento a Ŷayyān (Jaén), una de las 27 regiones de al-Andalus. Según esta interpretación de al-Muqaddasī , el Hišn Qasțalla se encontraría en una extensa llanura poco distante de Arjona, adoleciendo el lugar de escasez de agua, por lo que sus habitantes dedicaban al

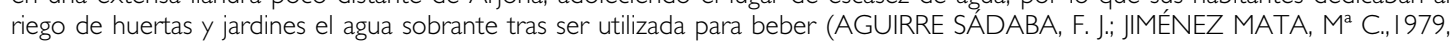
pp. 33 y 53$)$.
} 
De hecho, el castillo almohade, edificado para la defensa de los aldeanos y de sus ganados, dio paso, tras la conquista cristiana, a una fortaleza integrada en la red defensiva del Concejo de la ciudad de Jaén, y era Jaén, a través del gobierno municipal, quien tenía potestad absoluta sobre el castillo, su utilización, mantenimiento y nombramiento de su alcaide, sistemáticamente elegido entre la oligarquía de caballeros e hidalgos de la Ciudad. El papel de los aldeanos se reduce al servicio forzoso ${ }^{27}$. El cambio en la concepción de su uso y función se refleja en las remodelaciones llevadas a cabo en su planta y alzado. Así, se construirá en la zona sur de la fortificación un recinto independiente de tendencia triangular, con una torre en cada uno de sus vértices. Las tres torres están unidas por lienzos de muralla, que en su momento tuvieron adarve, pero que sólo se mantiene en algunos puntos. Dentro del sector sur, adosados al lienzo oeste, hay restos de una construcción, de la que sólo quedan los cimientos (FIGURA 9).

Por lo que se refiere al segundo tipo de asentamiento rural, el Cortijo, tiene, naturalmente, menor entidad poblacional que la aldea, aunque desconocemos cuántas familias podían vivir en ellos. Dentro de esta categoría se pueden diferenciar los que surgieron como el núcleo habitado de una sola heredad, y el que servía como centro de explotación y vivienda de los labradores de las diversas propiedades circundantes, aunque esta distinción no nos puede llevar, creemos, a conclusiones sobre el número de habitantes, ya que depende de la extensión de las tierras en explotación o del tipo de aprovechamiento de los recursos (agrícola, ganadero o mixto), que condicionan la cantidad de mano de obra necesaria.

Respecto a su tipología, los datos que poseemos son bastante escasos. El único cortijo bajomedieval excavado ( $y$, desgraciadamente sólo un sector de él) en Jaén es el de Peñaflor, revelándose como una construcción bastante sencilla, compartimentada en varias habitaciones con pavimento de cal grasa, que aprovechaba además una cueva como parte de la vivienda (SALVATIERRA CUENCA, AGUIRRE SADABA, CASTILLO ARMENTEROS, 1991; SALVATIERRA CUENCA, CASTILLO ARMENTEROS, 1993).

Por lo que se refiere a la información aportada por las fuentes escritas, una característica repetida en casi todos los casos documentados, es que la dehesa boyal asignada al cortijo se encontraba siempre cerca o colindando con su núcleo habitado, seguramente para garantizar la vigilancia del ganado que allí se encontraba.

Son numerosos los ejemplos, sobre todo en la Campiña Occidental, del Cortijo dotado de una torre defensiva, de planta cuadrada y construida normalmente en mampostería, aunque también está presente el tapial. En algunos casos, las estructuras defensivas poseen mayor entidad, constituyendo auténticos castillos. Tales son los ejemplos de la Muña, El Término, la Aldehuela, Fuentetétar, etc. (FIGURAS IO A I3).

A su similitud tipológica y constructiva debemos añadir otra característica recurrente, como es el hecho de que sean los asentamientos con una mención más temprana en las fuentes escritas. Efectivamente, la mayoría de ellos ya existían con toda seguridad en la primera mitad del siglo XIV, mientras que, los cortijos surgidos a partir del siglo $X V$ no cuentan con ningún tipo de fortificación.

Estas construcciones parecen, en muchas ocasiones, reutilizar elementos de fortificación adscribibles al último período de dominación musulmana, aunque siempre es difícil de asegurar esta permanencia, dadas las intensas modificaciones llevadas a cabo en estos asentamientos, de ocupación plurisecular, en la época Moderna y Contemporánea.

\footnotetext{
27 Aunque es una noticia tardía, de mediados del siglo XV contamos con un valiosísimo testimonio de esta situación. En I456, el concejo de Jaén le encarga a Jimeno de Berrio la tenencia del Castillo del Berrueco. Inmediatamente, ordena a los aldeanos que le reciban como alcaide, dándole un hombre de día y dos de noche para las guardias, so pena de 12 maravedíes por cada vez que alguno no fuese; deberían obedecerle en todo y entregar semanalmente en la fortaleza dos o tres cargas de leña; a cambio de esto, les eximen de pagar velas, rondas y guardas en las puertas de Jaén (PORRAS ARBOLEDAS, 1990, nota $n^{\circ}$ |44).
} 
Estos asentamientos agrarios fortificados serían reutilizados por los cristianos, en la segunda mitad del siglo XIII, para construir los núcleos de habitación de las heredades repartidas, siguiendo una tipología común a otras tierras fronterizas, como por ejemplo, las tierras manchegas más orientales, las murcianas, las cordobesas, etc.

Respecto a la articulación del poblamiento en la Tierra de Jaén, la primera característica que resulta evidente (ver FIGURA 7) es la existencia de un doble desequilibrio en su distribución zonal, que se mantendrá durante toda la Baja Edad Media: En primer lugar, entre las Sierras del Sur y las Zonas de Campiña y Valle; en segundo, entre las Campiñas Occidental y Oriental.

Las Sierras Sur de Jaén, sector de fricción fronteriza con el Reino Nazarí de Granada, serán un auténtico desierto poblacional desde la conquista castellana del territorio hasta el primer tercio del siglo XVI, en el que, comenzará su repoblación, siendo dirigida por el concejo jiennense.

Los dos únicos núcleos de población conquistados por los castellanos en este sector, que permanecerán durante todo el período en manos cristianas y poblados serán, por una parte, La Guardia, cabeza del señorío del mismo nombre, y Pegalajar, única aldea del realengo jiennense en las sierras, hasta la definitiva conquista de Cambil y Alhabar, en 1485.

Las Sierras constituirán, pues, la "tierra de nadie" en las que llevar los ganados a pastar cuando los períodos de tregua lo permitían. El bastión jiennense más adelantado en el sector sureño será el Castillo de Otíñar, cuya función era vigilar el camino Viejo de Granada, que desde el río Campillo iba desde Cazalla a desembocar en el Valdearazo por la Cañada de las Azaillas.

Por lo que se refiere a las campiñas, la Occidental aglutinará la mayor parte del poblamiento, al contrario que la Oriental, mucho más despoblada durante todo el período bajomedieval y cuya ocupación se concentrará sobre todo en el siglo XV. Sólo una aldea, Villargordo, se localizaba en la Campiña Oriental, y ésta en el límite con lo que podemos considerar Valle del Guadalquivir.

Las razones de este desequilibrio en la distribución del poblamiento rural entre ambas campiñas hay que buscarlas, en primer lugar, en las diferentes características geológicas y de calidad del suelo que las distinguen. La Campiña Oriental presenta unos suelos bastante más pobres, y una mayor escasez de agua potable, dada la salinidad de los arroyos que la recorren, que, además, son más escasos que en la Campiña Occidental.

A ello se une, además, otras razones, esta vez de tipo histórico y social. Los castellanos heredaron una distribución de la población que ya se daba en el período almohade. Tras la conquista, los cristianos repartieron aquellas tierras que se hallaban puestas en cultivo y roturadas, que se concentraban, sobre todo en la Campiña Occidental, ya que las prospecciones arqueológicas llevadas a cabo al este del río Guadalbullón han revelado que los asentamientos de la última etapa islámica, bastante escasos, se concentraban a lo largo del Arroyo Salado de Torrequebradilla, relacionados seguramente con la explotación ganadera y de las salinas.

Hasta finales del siglo $X V$, no comenzó la roturación de nuevas tierras, ya que la presión demográfica no había sido, hasta la definitiva pacificación del territorio, suficiente para justificar esa empresa. De hecho, buena parte de la Campiña Oriental estuvo ocupada, desde la primera mitad del siglo XIV por la Dehesa del Riez. Así mismo, las heredades constatadas en esta campiña tenían una vocación ganadera indudable. Por otra parte, también influyó en la roturación y puesta en cultivo de la Campiña Oriental, el renovado interés de la oligarquía de hidalgos y caballeros en captar más rentas de sus propiedades fundiarias, una vez que una de sus principales fuentes de riqueza, la guerra y las incursiones de saqueo en territorio nazarí, cesaron. Uno de sus métodos fue también el agrandar sus heredades a través de la usurpación de los terrenos incultos comunales. 
Naturalmente, a lo largo de los siglos bajomedievales se siguió un proceso de ordenación y jerarquización espacial de estos asentamientos cristianos. Sobre La Tierra de Jaén, cuyos límites no terminarán de definirse ni tan siquiera al terminar la lucha contra Granada a finales del siglo $X V$, se constituye mediante creación o reutilización, un conjunto de núcleos rurales vinculados entre sí por una cadena jerárquica que, a su vez, ordena el territorio en torno a cada uno de ellos. La jerarquía de los núcleos está constituida, en Jaén, por tres tipos de entidades: Ciudad, Aldeas y Cortijos.

Jaén, centro administrativo, sede del poder local, fortaleza y, rápidamente, sede episcopal; lugar privilegiado por los reyes con la concesión de ser la ciudad en la que se hará el reparto y la venta de los botines de guerra obtenidos por las acciones de guerra protagonizados por los concejos del obispado.

En segundo lugar, estarían las aldeas de su término. Desde finales del siglo XIII y a lo largo del siglo XIV, durante las minorías de edad de Fernando IV y Alfonso XI, y la Guerra entre Pedro I y Enrique de Trastámara, se produjo un considerable fortalecimiento de la nobleza urbana, auténtica oligarquía que se apropia de tierras, aldeas y derechos jurisdiccionales, que pasan a manos privadas a costa de la propiedad realenga. Este proceso nos informa de la preeminencia del concejo urbano sobre el territorio aldeano. Efectivamente, tanto la asignación de este territorio como el control del uso de partes importantes del mismo, corresponde, con toda probabilidad, a la oligarquía de hidalgos y caballeros que conforman la asamblea ciudadana.

Este poder eminente es refrendado por el rey, ya que la monarquía -cuya autoridad directa sobre el Concejo queda garantizada por el fuero toledano-, siempre necesitará de apoyos en estos siglos convulsos, además de garantizar así la presencia en la frontera de una casta de guerreros.

De esta forma, las comunidades vecinales de cada aldea reciben el dominio directo sobre el terrazgo aldeano, pero es el concejo urbano el que por su derecho eminente, puede proceder a la enajenación de parte o de la totalidad de la unidad de aldea. Paralelamente, puede restringir o abrir a otros residentes en el conjunto de Jaén determinados espacios de uso colectivo del término aldeano, como su dehesa, o sus fuentes de agua potable, por ejemplo.

Respecto a la última unidad, el Cortijo, las fuentes escritas más antiguas con las que contamos son de 1378, y están incluidas en el Libro de Las Dehesas, transcrito y estudiado por el prof. Tomás Quesada. El documento es de enorme interés, pues aporta el cuerpo básico de cortijos que disponían de dehesa boyal propia. Eran cortijos surgidos en una explotación agrícola, centrada en el cultivo de cereal. La concesión de dehesas boyales también era una facultad del concejo de la ciudad, ya desde principios del siglo XIV.

La lista de cortijos supera la treintena, y sus topónimos, en muchos casos siguen existiendo en la actualidad, por lo que la prospección arqueológica unida a la información aportada por este magnífico documento, nos ha ayudado a reconstruir una buena parte de la organización espacial agraria del Concejo, así como su atribución social, al menos desde el último cuarto del siglo XIV.

Ciudad, aldeas y cortijos no permanecieron inalterados a lo largo de la Baja Edad Media. En la ciudad de Jaén se dejó sentir, de forma desigual pero creciente, el protagonismo de la voluntad política en su configuración física, substrayendo a la propia comunidad urbana la posibilidad de dar forma física a su asentamiento. Observándose este proceso en el trazado de nuevas calles, en la ocupación de los mejores solares urbanos, etc. Las aldeas tuvieron desigual suerte. Algunas de ellas permanecen incluso en la actualidad. Otras redujeron sus dimensiones a simples cortijadas o incluso desaparecieron a lo largo del siglo XVI. Algunos de los cortijos crecieron hasta convertirse durante los siglos $X V$ y $X V I$ en aldeas, otros se convirtieron en grandes torres de señorío, como en el caso de El Término, pero esto ya es otra historia y supera los límites y los objetivos de este artículo. 


\section{BIBLIOGRAFÍA}

AGUIRRE SÁDABA, F.J., (1982): "El Jaén islámico", W.AA.: Historia de Jaén. Jaén, Pp. 163-203.

AGUIRRE SÁDABA, F. J.; JIMÉNEZ MATA, Ma C., (1979): Introducción al Jaén Islámico (Estudio Geográfico - Histórico). Diputación Provincial. Instituto de Estudios Giennenses. Jaén.

ALFONSO X, rey de Castilla: Primera Crónica General de España. Editada por Ramón Menéndez Pidal; con estudio actualizador de Diego Catalán. 2 vols. Universidad Complutense. Madrid. 1977, 743 p.

ARGOTE DE MOLINA, G., (1588): Nobleza de Andalucía. Reedición de la realizada en Jaén en I866, corregida y anotada por Manuel Muñoz Garnica. Riquelme y Vargas Ediciones, S.L., Jaén, I991.

CASTILLO ARMENTEROS, J.C.; LARA JIMÉNEZ, J.C.; CASTILLO ARMENTEROS, J.L., (1989): "La delimitación occidental del iqlim de Jaén: documentos escritos, toponimia y arqueología", III Congreso de Arqueología Medieval Española. T. II. Oviedo, pp. 369-375.

CAZABÁN LAGUNA, A., (1924): "El castillo de Espeluy", Don Lope de Sosa: Crónica mensual de la Provincia de Jaén. Riquelme y Vargas. Jaén, p. 336.

CHAMOCHO CANTUDO, M.A.(1997): "Los privilegios de la Ciudad de Jaén en la Baja Edad Media", SAINZ GUERRA, J. (Ed.): La aplicación del Derecho a lo largo de la historia. Actas de las II Jornadas de Historia del Derecho. Universidad de Jaén. Jaén, pp. 291-319.

CHAMOCHO CANTUDO, (1998): Justicia Real y Justicia Municipal: la implantación de la justicia real en las ciudades giennenses (I 234-1 505). Diputación Provincial de Jaén. Instituto de Estudios Giennenses. Jaén.

ESPINALT GARCÍA, B., ( 1775): Atlante Español.

GARCÍA DE CORTÁZAR, J.A.,(1988): "Organización social del espacio: propuestas de reflexión y análisis histórico de sus unidades en la España Medieval', Studia Historica, $H^{a}$ Medieval. N ${ }^{\circ}$ VI. Universidad de Salamanca. Salamanca, pp. 195-236.

GARCÍA GALLO, A., (1975): "Los Fueros de Toledo", Anuario de Historia del Derecho Español. T. XLV. Instituto Nacional de Estudios Jurídicos. Madrid, pp. 34|-488.

GONZÁLEZ GONZÁLEZ, J., (1980-1986): Reinado y diplomas de Fernando III. 3 vols. Monte de Piedad y Caja de Ahorros. Córdoba.

GONZÁLEZ JIMÉNEZ, M., (1977): "Propiedades y rentas patrimoniales del cabildo de la catedral de Sevilla a fines de la Edad Media", Cuadernos de Historia, Anexos de la Revista Hispania. № 7. Madrid, pp. 167-212.

GONZÁLEZ JIMÉNEZ, M., (1980): Historia de Andalucía. V. II. Barcelona-Madrid.

GONZÁLEZ JIMÉNEZ, M., (1988): En torno a los orígenes de Andalucía. La repoblación del siglo XIII. $2^{\text {a }}$ edición. Universidad de Sevilla. Sevilla.
GONZÁLEZ JIMÉNEZ, M., ( 1987$)$ : "Repartimientos andaluces del siglo XIII. Perspectiva de conjunto y problemas", Historia, Instituciones, Documentos. № 14. Universidad de SeviIla. Sevilla, pp. 103-12I.

GONZÁLEZ JIMÉNEZ, M., (|99|): Diplomatario andaluz de Alfonso $X$. Sevilla.

HIGUERAS MALDONADO, J., (1974): Documentos latinos del siglo XIII al XVII en los archivos de Baeza (Jaén). Transcripción, traducción y comentario Lingüistico. Diputación Provincial de Jaén. Instituto de Estudios Giennenses. Jaén.

JIMÉNEZ SÁNCHEZ, M., QUESADA QUESADA, T., (1992): "En los confines de la conquista castellana: Toponimia y poblamiento de los montes granadino-giennenses en el siglo XIII según la documentación cristiana", Revista del Centro de Estudios Históricos de Granada y su Reino. No 6. $2^{\text {a }}$ E. Granada, pp. 59-63.

MADOZ, P. (1845-1850): Diccionario Geográfico-estadísticohistórico de España y sus posesiones de Ultramar. SÁNCHEZ ZURRO, Domingo (Ed.): Diccionario Geográfico-histórico de Andalucía: Jaén. Reproducción Parcial del Diccionario Geográfico-estadístico-histórico de España y sus Posesiones de Ultramar. Ámbito D.L. Valladolid. 1988.MARCOS BURRIEL, A., (I800): Memorias para la vida del Santo rey Don Fernando III.

MARCOS BURRIEL, A., (I800): Memorias para la vida del Santo rey Don Fernando III. Anotadas y editadas por Miguel de Manuel Rodríguez. Reedición facsímil de El Albir. Barcelona, 1974

ORTEGA Y COTES, I.J. y DE ORTEGA ZÚÑIGA Y ARANDA, P. (eds.), ( 1762): Bulario de la Orden Militar de Calatrava. Reedición El Albir S.A. Barcelona, 198I.

PÉREZ MARTÍNEZ, Ma C.; ALCÁZAR HERNÁNDEZ, E., (1993): "Aproximación al urbanismo de Jaén en el siglo XI", SALVATIERRA, V, CASTILLO, J.C.; CASTILLO j.L:: El baño árabe del Naranjo y la formación del edificio Los Caños. Granada, pp. |4|-| 47.

PORRAS ARBOLEDAS, P., (1990): "La aristocracia urbana de Jaén bajo los Trastámara: los Mendoza y los Berrio", En la España Medieval. № 13. Universidad Complutense. Madrid, pp. 27|-30।.

QUESADA QUESADA, T., (1989): "La época bajomedieval", VV.AA.: Jaén. Vol. II, Historia. Andalucía D.L. Granada, pp. 49I-520.

QUESADA QUESADA, T., (1994): El Paisaje rural de la Campiña de Jaén en la Baja Edad Media según los Libros de las Dehesas. Universidad de Jaén. Jaén.

RODRÍGUEZ MOLINA, J., (1986): El Obispado de BaezaJaén. Organización y economía diocesanas (siglos XIII-XVI). Diputación Provincial. Jaén.

RODRÍGUEZ MOLINA, J. (ed), (1983): Colección Diplomática de Baeza (siglos XIII-XV). Jaén (ciclostilado).

ROUDIL, J., (1962): El fuero de Baeza. Edición, estudio y vocabulario. Publicaciones del Instituto de Estudios Hispánicos, portugueses e lberoamericanos de la Universidad Estatal de Utrecht (Holanda). Van Goor Zonen. La Haya. 
RUIZ RODRÍGUEZ, A.; MOLINOS MOLINOS, M.; RÍSQUEZ CUENCA, C., (1998): "Paisaje y territorio mundo: dos dimensiones de una misma teoría arqueológica", V Coloquio Internacional de Arqueología Espacial: Arqueología del Paisaje. Arqueología Espacial. No 19-20. Seminario de Arqueología y Etnología Turolense. Instituto de Estudios Turolenses. Teruel, pp. 21-32.

RUS PUERTA, F. DE, ( I 646): Corografia Antigua y Moderna del Reino y Obispado de Jaén. Edición, estudio preliminar, revisión e índices: J. Latorre García, J. Cañones Cañones y J. A. López Cordero. U.N.E.D. Jaén, 1998.

SALVATIERRA CUENCA, V., (1993): "Jaén en los siglos XIII y XIV. La formación de la ciudad cristiana", Revista del Centro de Estudios Históricos de Granada y su Reino. N 7. Granada, pp. 149-167.

SALVATIERRA CUENCA, V. (Ed.), (1995): Guía Arqueológica de la Campiña de Jaén. Granada.

SALVATIERRA CUENCA, V.; AGUIRRE SADABA, F.J.; CASTILLO ARMENTEROS, J.C., (199I): "Excavaciones en el Cerro del Castillo de Peñaflor (Jaén)", Anuario Arqueológico de Andalucía - 1989. T. II. Actividades Sistemáticas. Informes y Memorias. Consejería de Cultura. Dirección Gral de BB.CC. Sevilla, pp. 298-303.
SALVATIERRA CUENCA, V.; CASTILLO ARMENTEROS, J.C., (1993): "Il Campaña de excavaciones en el yacimiento medieval del Cerro del Castillo de Peñaflor", Anuario Arqueológico de Andalucía - 199I. T. II. Actividades Sistemáticas. Informes y Memorias. Consejería de Cultura. Dirección Gral de BB.CC. Sevilla, pp. 3/2-3।8.

SANZ SANCHO, I., (1995): Geografía del Obispado de Córdoba en la baja Edad Media. Ediciones de la Universidad Autónoma de Madrid - Ediciones Polifemo. Madrid.

SEGURA MORENO, M., (1976): Estudio del Códice Gótico (siglo XIII) de la Catedral de Jaén. Transcripción y Traducción de sus documentos latinos y romances. Diputación Provincial. Instituto de Estudios Giennenses. Jaén.

XIMENA JURADO, M., ( 1654$)$ : Catálogo de los Obispos de las Iglesias Catedrales de la Diócesis de Jaén y Annales Eclesiásticos deste Obispado. Edición facsímil y estudio preliminar e índices de J. Rodríguez Molina Y J. Ma Osorio Pérez. Servicio de Publicaciones de la Universidad. Granada, |99|.

XIMENA JURADO, M., ( 665 ): Historia o anales del municipio Albense Urgavonense o villa de Arjona. Ed. de Rafael Frías Martín. Jaén 1996. 


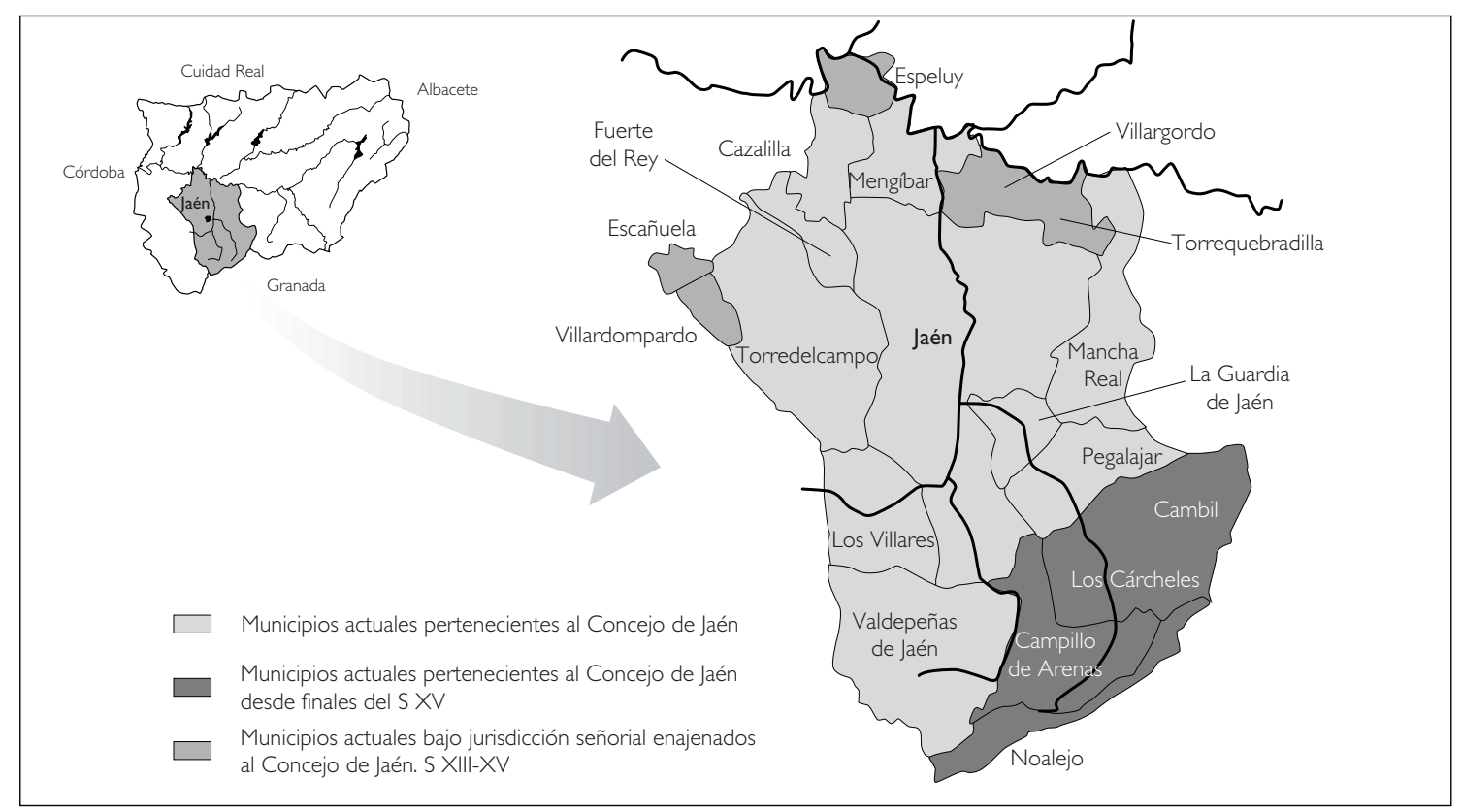

Fig. I. Dominio territorial del Concejo bajomedieval de Jaén, con relación a la actual Provincia de Jaén

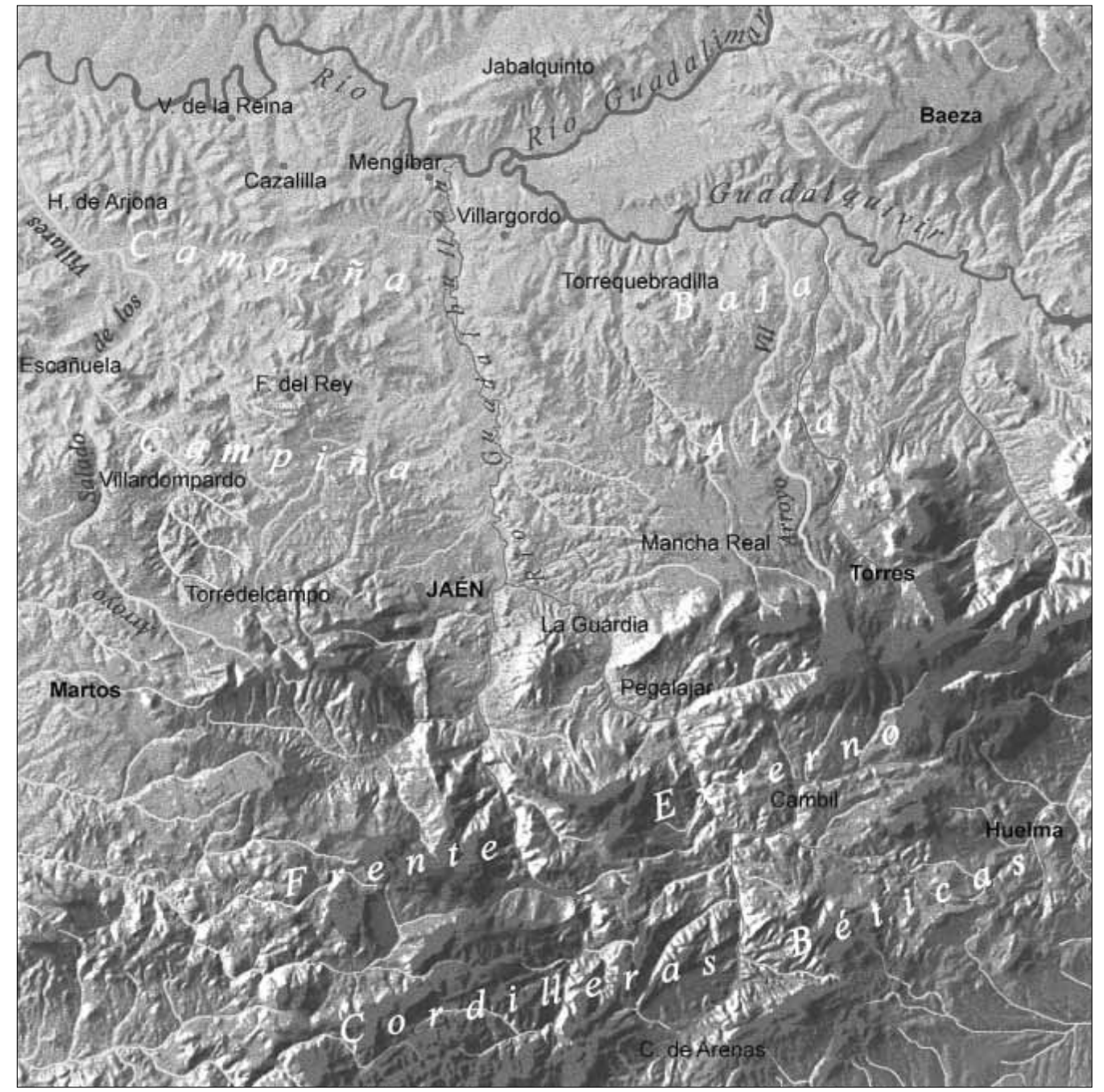

Fig. 2. Contexto geográfico del Concejo Bajomedieval de Jaén 


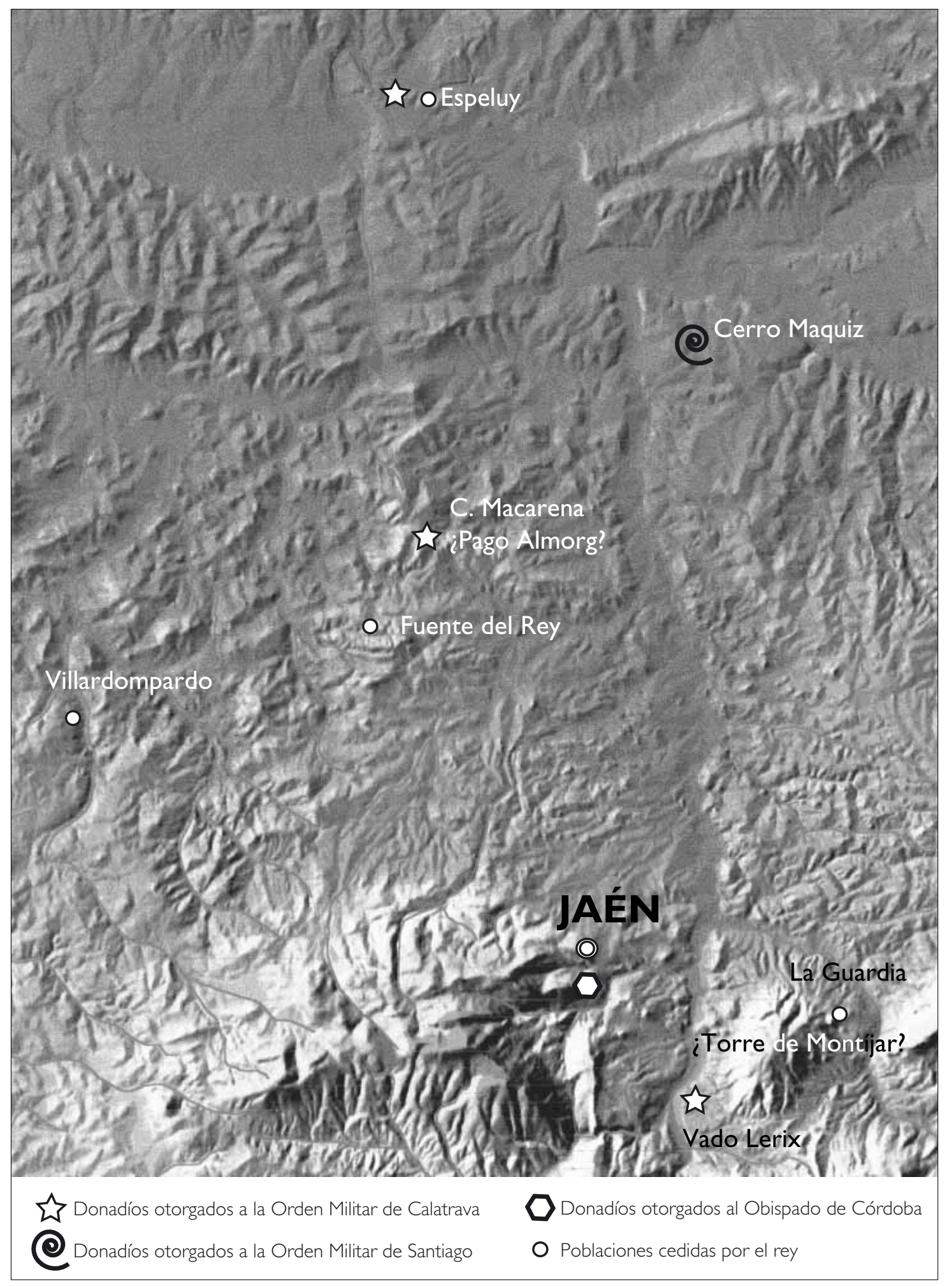

Fig. 3. Posible localización de algunos de los donadíos concedidos por Fernando III 


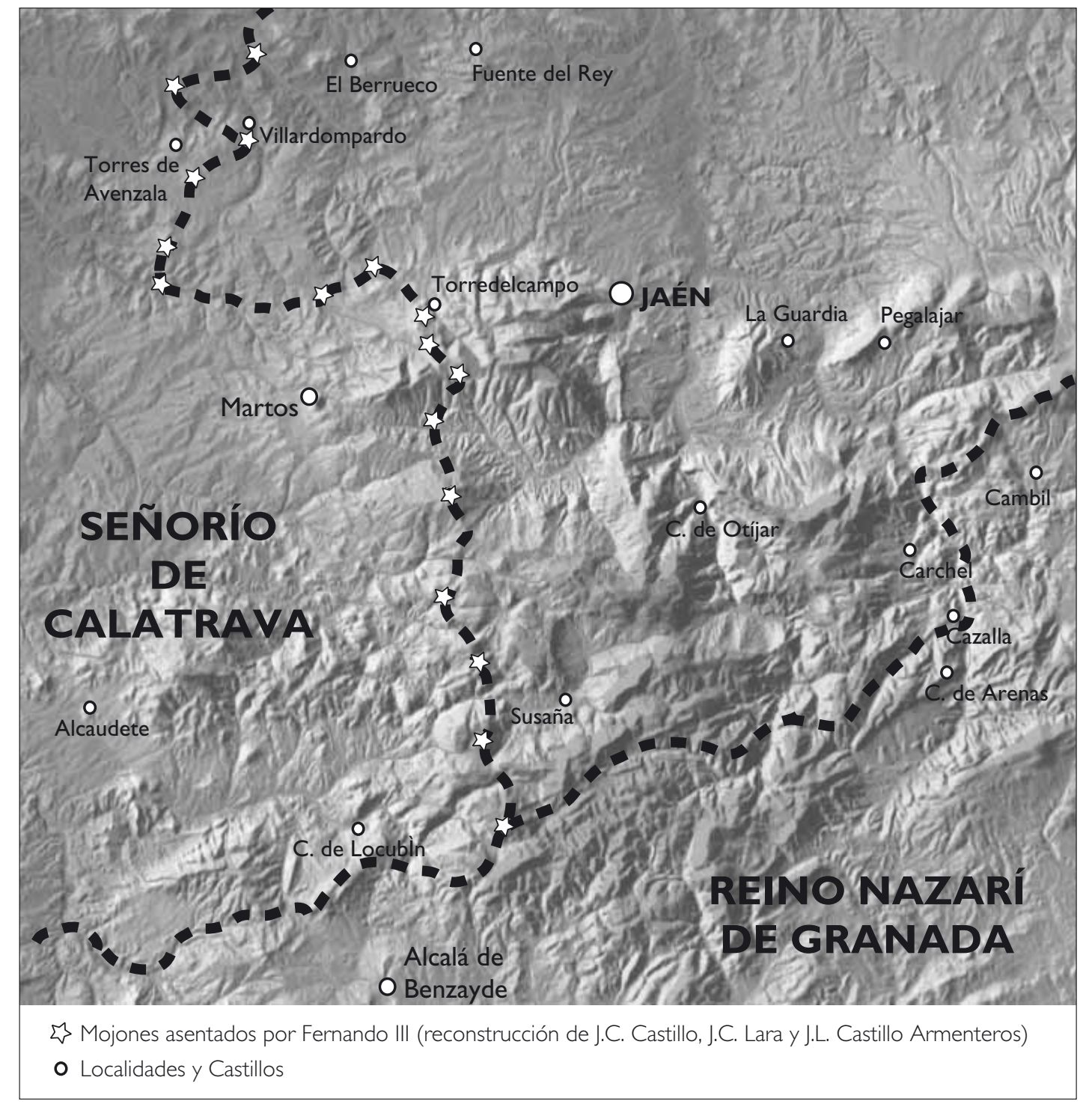

Fig. 4. Límite SW del Concejo de Jaén en I25I 


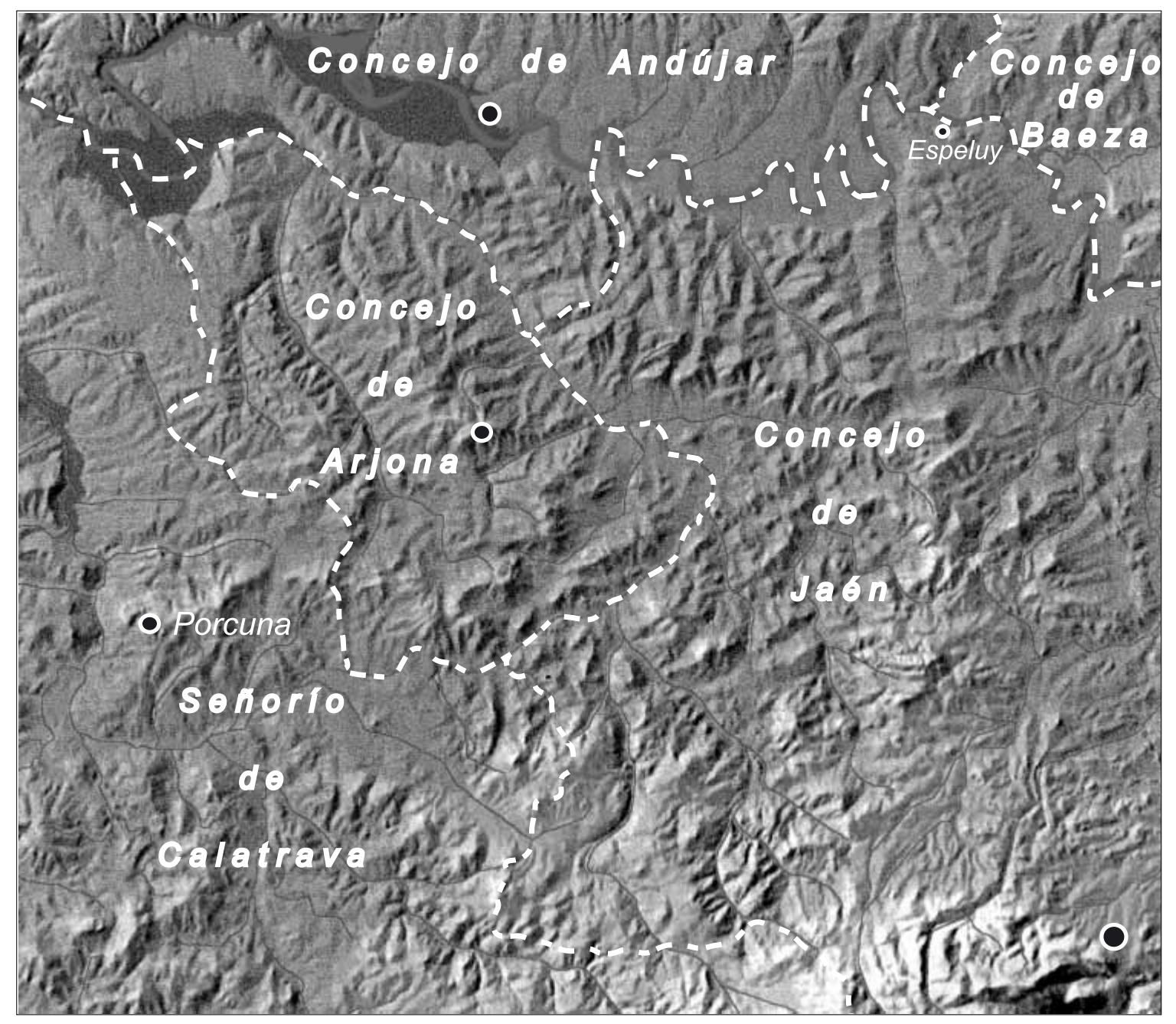

Fig. 5. Límite NW del Cocejo de Jaén en 1251 


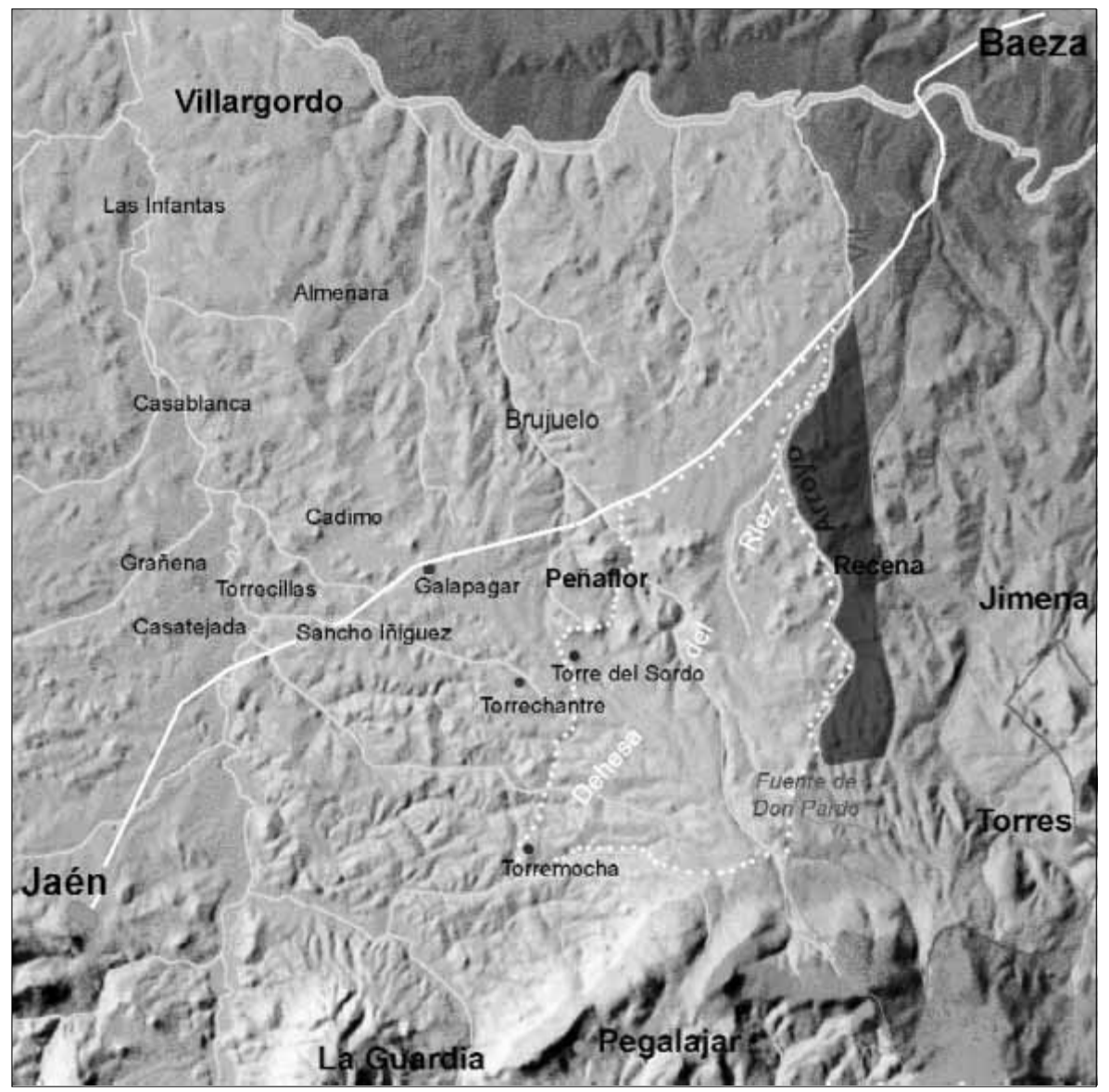

Fig. 6. Campiña Oriental de Jaén en 1338. Al Este de la Dehesa del Riez hemos evidenciado en color más oscuro los terrenos usurpados por los de Jaén al concejo baezano 


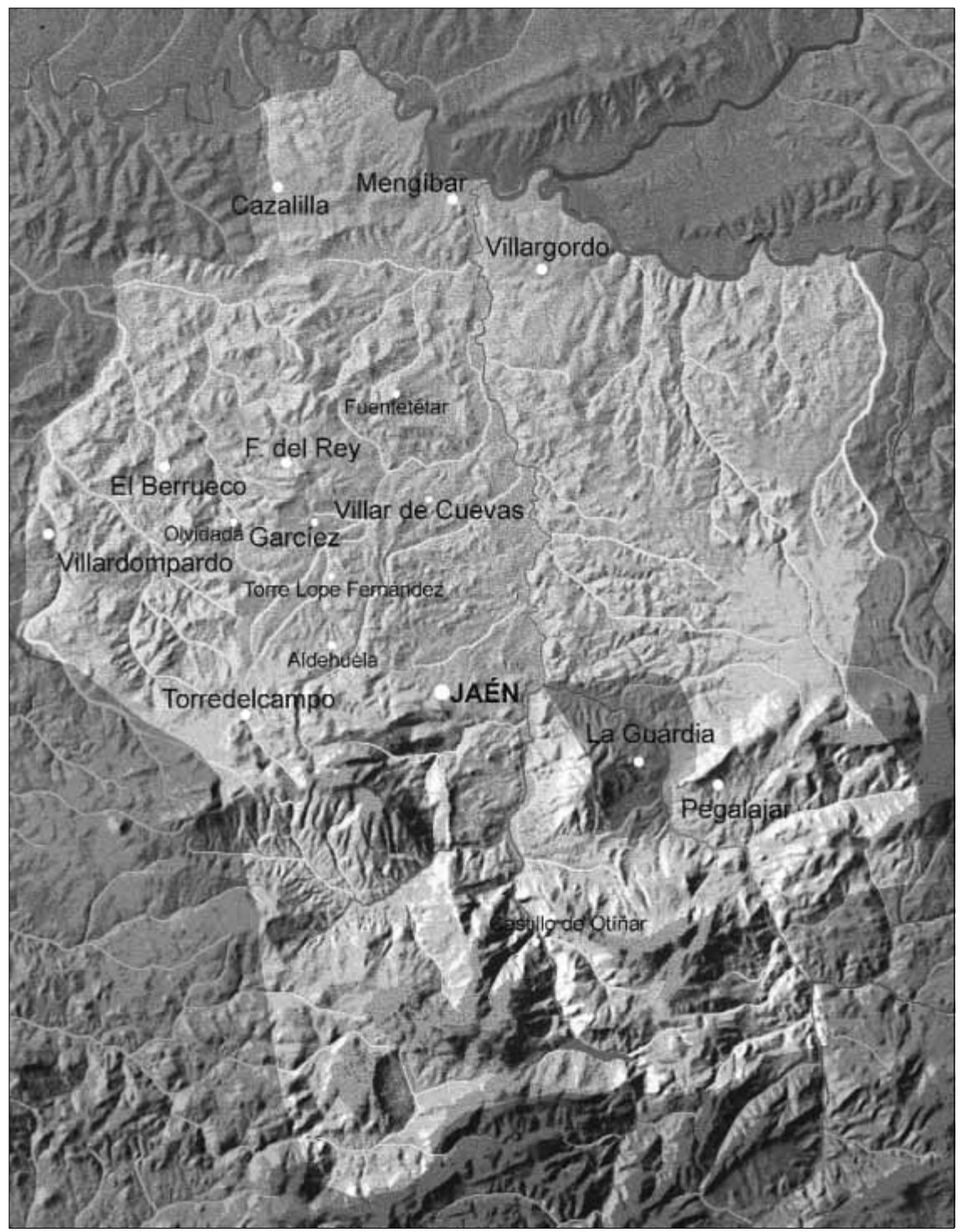

Fig. 7. Aldeas de Jaén a principios del S. XIV 


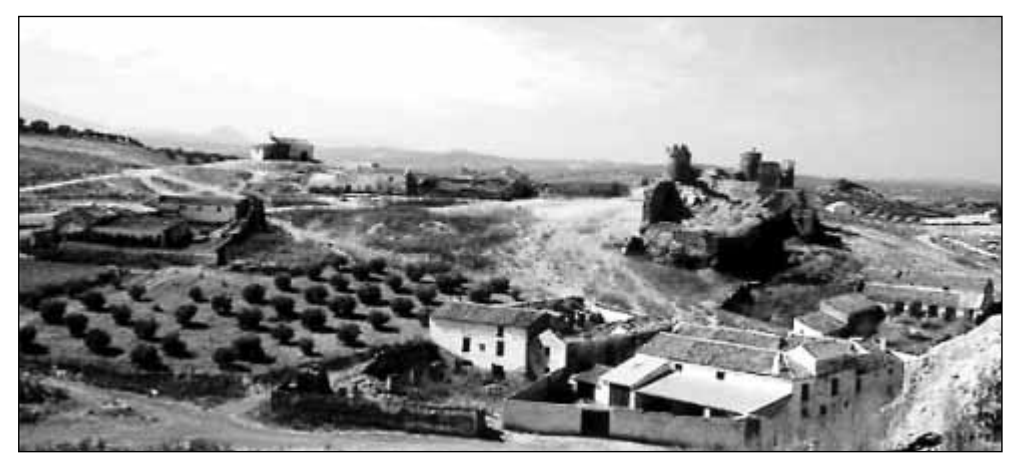

Fig. 8. Actual Cortijada y

Castillo del Berrueco

Fig. 9. Croquis de la planta del castillo del Berrueco realizado por J.C. y J.L. Castillo Armenteros, a partir de un dibujo original de J. Eslava Galán
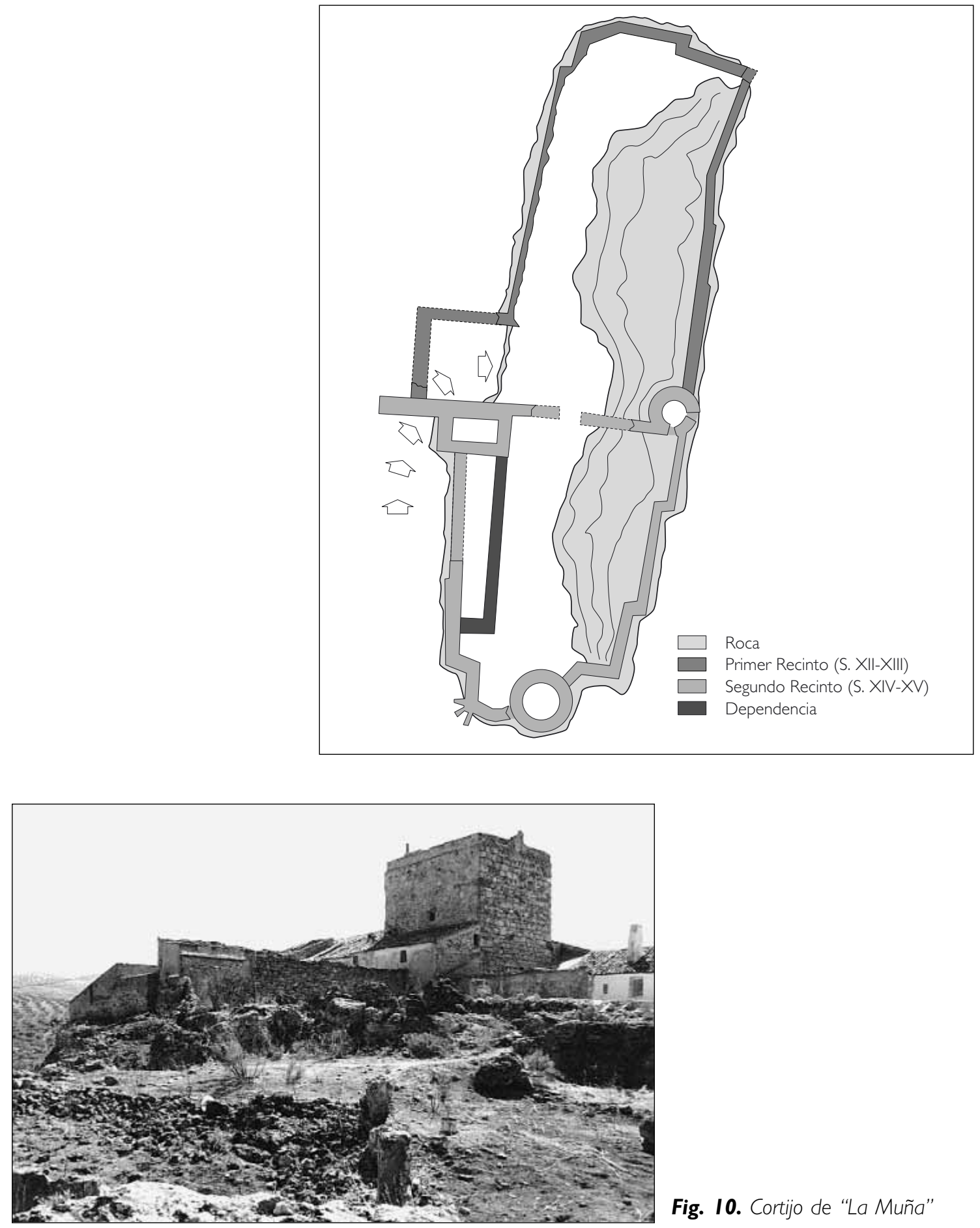

Fig. I0. Cortijo de "La Muña" 


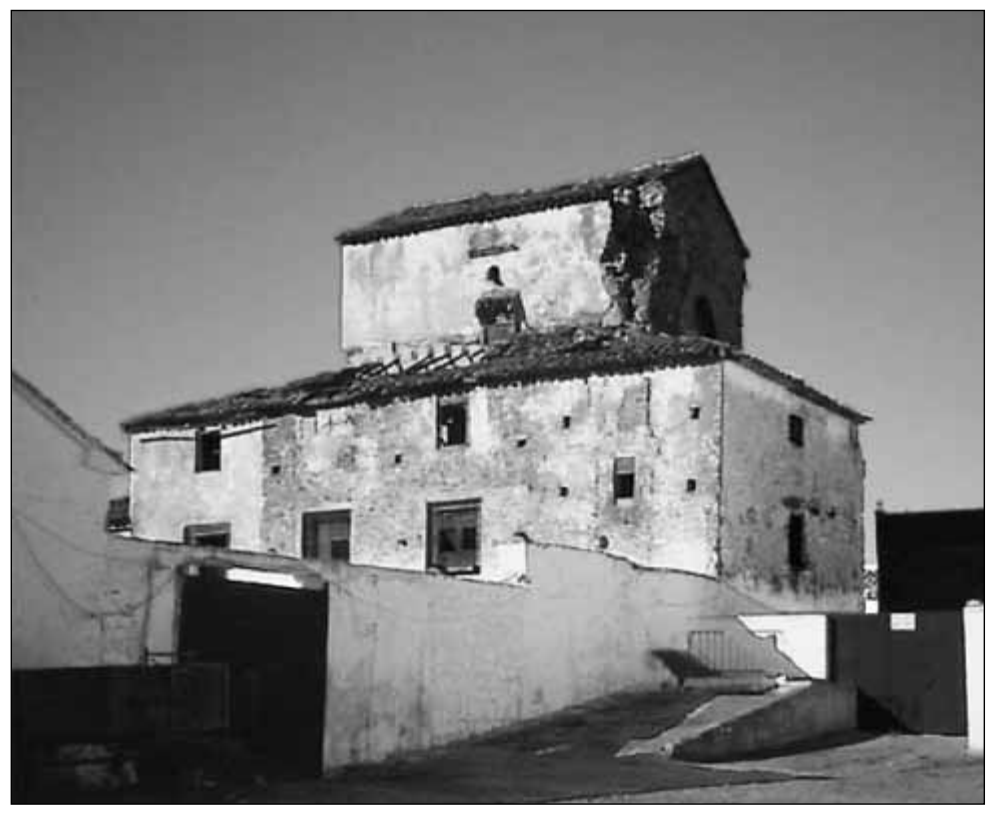

Fig. II. Cortijo de "El término"

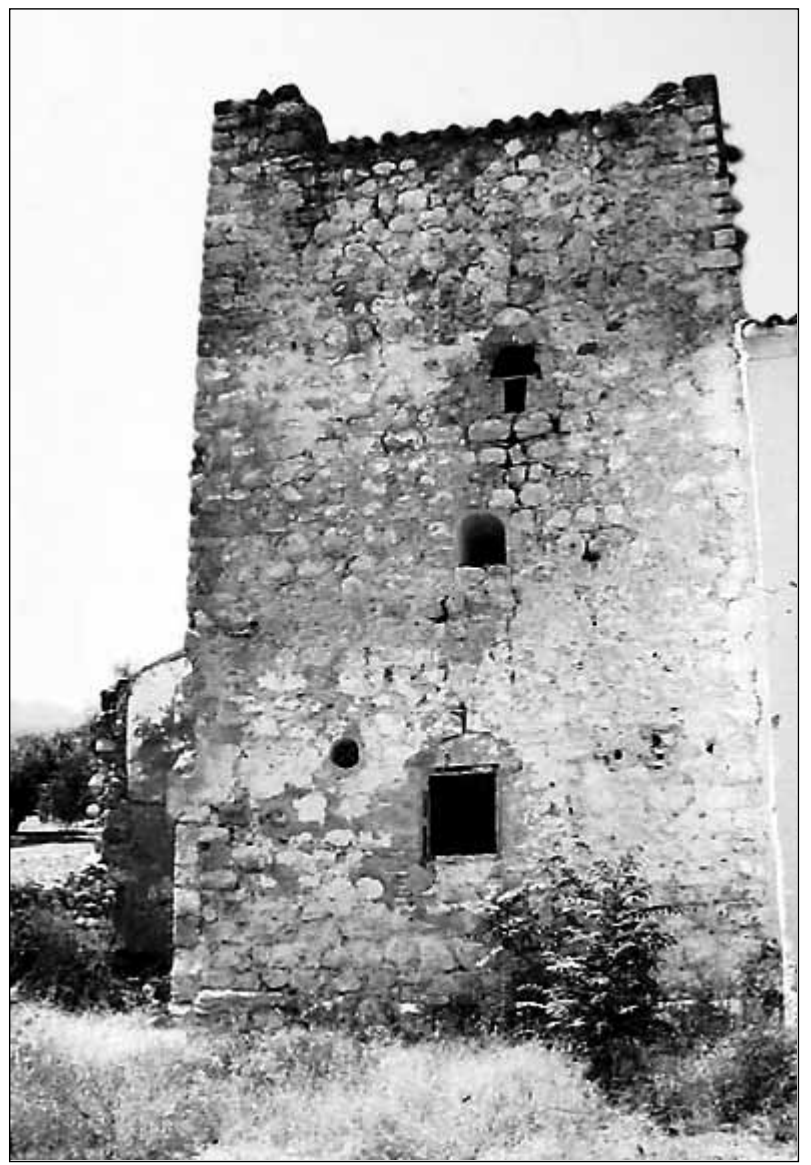

Fig. 12. Cortijo de "La Aldehuela" 


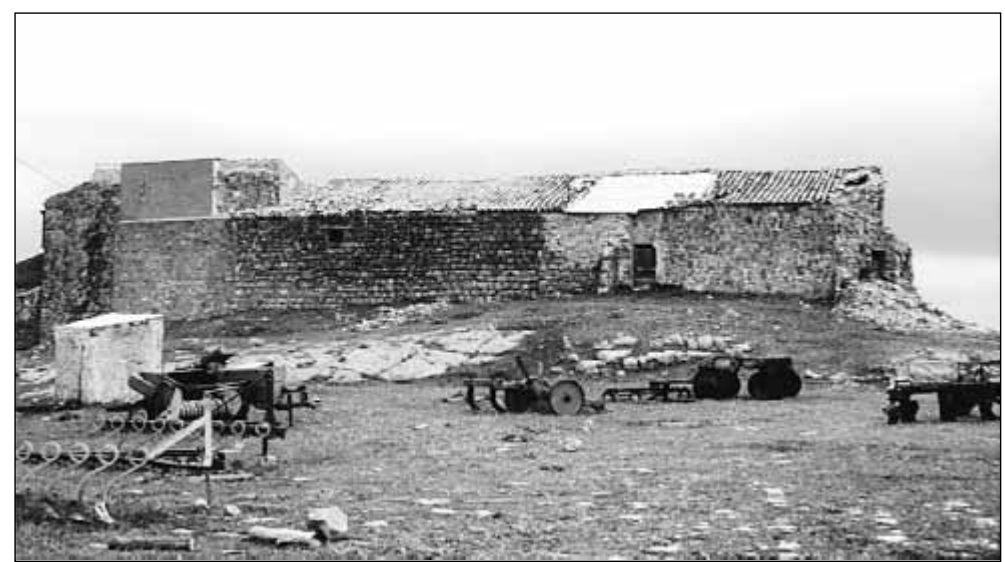

Fig. I3. Cortijo de "Fuentetétar" 